\title{
LA INFORMACIÓN DE LAS CUENTAS SATÉLITE DE AMBIENTE EMITIDA EN COLOMBIA (1995 - 2010): UNA REVISIÓN CRÍTICA*
}

\author{
JENNIFER LORENA GÓMEZ CONTRERAS**, CLAUDIA LUCÍA NIÑO GALEANO**** \\ \& JULY CAROLINA ROJAS GÓMEZ***** \\ UNIVERSIDAD NACIONAL DE COLOMBIA
}

Recibido/ Received/ Recebido: 07/02/2012 - Aceptado/ Accepted / Aprovado: 01/05/2012

\section{Resumen}

El objetivo de este artículo es analizar la pertinencia de la información emitida por el Sistema de Cuentas Satélites de Ambiente para la formulación de la política pública ambiental en Colombia entre 1995-2010. En este sentido, se realizó una investigación cualitativa de tipo analítico de la información, en la que tanto los datos como la literatura disponible fueron objeto de revisión y evaluación crítica. Se concluye que la información emitida por el DANE es limitada para las cuestiones ambientales que se perciben como prioritarias en Colombia, dado que se refiere fundamentalmente a aspectos relativos a las actividades extractivas como la minería y no tiene en cuenta el contexto social. Además, se evidencia que la información recogida se dirige a una política pública ambiental orientada básicamente hacia los mercados, en lugar de los intereses sociales. Finalmente, se hace un llamado para que el Sistema de Cuentas Satélites de Ambiente sea utilizado apropiadamente para efectos de la formulación de políticas públicas ambientales que respondan a los intereses de la sociedad.

Palabras clave: cuentas nacionales, información ambiental, política pública ambiental, sistema de cuentas satélites de ambiente.

\section{INFORMATION PRODUCED BY ENVIRONMENTAL SATELLITE ACCOUNTS IN COLOMBIA (1995 - 2010): A CRITICAL}

\begin{abstract}
The objective of this article is to analyze the relevance of the information produced by the System of Environmental Satellite Accounts for environmental public policy formulation in Colombia through 1995 - 2010. According to this, the information was subject to a qualitative-analytic research, in which both available data and literature were reviewed and critically evaluated. The conclusion is
\end{abstract}

* El presente artículo se deriva del proceso de revisión bibliográfica realizado como parte del proyecto de investigación titulado "Aportes y vacíos de la información de las Cuentas Nacionales Ambientales para la formulación de políticas públicas ambientales en Colombia entre 1995 y 2010", con código Hermes: 12423, el cual fue realizado durante los meses de Marzo de 2011 a Enero de 2012, financiado por el Fondo de Investigación Jesús Antonio Bejarano de la Universidad Nacional de Colombia-Sede BogotáFacultad de Ciencias Económicas.

** Contadora Pública y estudiante de la Maestría en Administración con énfasis en investigación de la Universidad Nacional de Colombia. Co-investigadora en la Universidad Nacional de Colombia. Miembro del Grupo INTERGES de la Universidad Nacional de Colombia. Correo electrónico: jlgomezc@unal.edu.co

*** Contadora Pública de la Universidad Nacional de Colombia, estudios avanzados en economía financiera de Universidad Autónoma de Madrid. Docente tiempo completo en el Programa de Contaduría Pública de la Facultad de Ciencias Económicas-Universidad Nacional de Colombia. Miembro del Grupo INTERGES de la Universidad Nacional de Colombia. Correo electrónico: clninog@ unal.edu.co

**** Contadora Pública y estudiante de la Maestría en Medio Ambiente y Desarrollo de la Universidad Nacional de Colombia. Coinvestigadora en la Universidad Nacional de Colombia. Miembro del Grupo INTERGES de la Facultad de Ciencias Económicas y del Grupo Cultura y Ambiente de la Facultad de Ciencias Humanas de la Universidad Nacional de Colombia. Correo electrónico: jcrojasg@unal.edu.co 
that the information provided by DANE is limited for the environmental aspects considered important in Colombia, because it just refers to aspects related to extraction activities such as mining, and it does not consider the social context. Also, the evidence shows that the information collected is oriented to an environmental public policy towards markets, instead of social interests. Finally, an appeal is made in order to encourage the System of Environmental Satellite Accounts to be properly used to formulate environmental public policies which respond to society interests.

Keywords: national accounts, environmental information, environmental public policy, system of environmental satellites accounts.

\title{
INFORMAÇÃO EMITIDA PELO CONTAS SATÉLITES DE AMBIENTE NA COLÔMBIA (1995 - 2010): UMA CRÍTICA
}

\begin{abstract}
Resumo
O objetivo deste artigo é analisar a pertinência da informação emitida pelo Sistema de Contas Satélites de Ambiente para a formulação da política pública ambiental na Colômbia entre 1995-2010. Neste sentido, realizou-se uma pesquisa qualitativa de tipo analítica da informação, na que tanto os dados como a literatura disponível foram objeto de revisão e avaliação crítica. Concluiu-se que a informação emitida pelo DANE é limitada para as questões ambientais que se percebem como prioritárias na Colômbia, dado que se refere fundamentalmente a aspectos relativos às atividades extrativistas como a mineração e não considera o contexto social. Além do mais, se evidencia que a informação reunida se dirige a uma política pública ambiental orientada basicamente para os mercados, em detrimento dos interesses sociais. Finalmente, faz-se um chamado para que o Sistema de Contas Satélites de Ambiente seja utilizado apropriadamente para efeitos de formulação de políticas públicas ambientais que respondam aos interesses da sociedade.

Palavras chave: contas nacionais, informação ambiental, política pública ambiental, sistema de contas satélites de ambiente.

Gómez, J. Niño, C. \& Rojas, J. (2012) La información de las cuentas satélite de ambiente emitida en Colombia (1995 - 2010): una revisión crítica. En: Revista de la Facultad de Ciencias Económicas de la Universidad Militar Nueva Granada. rev.fac.cienc.econ, XX (1)
\end{abstract}

JEL: M14, J15, J16, J30, J50.

\section{Introducción}

En este documento se presentan los resultados finales del proyecto de investigación "Aportes y vacíos de la información de las Cuentas Nacionales Ambientales para la formulación de políticas públicas ambientales en Colombia entre 1995-2010", el cual hace parte de la línea "Contabilidad económica, sociedad y ambiente" del Grupo de Investigación Estudios Interdisciplinarios sobre Gestión- INTERGES, adscrito a la Escuela de Administración de Empresas y Contaduría Pública de la Facultad de Ciencias Económicas de la Universidad Nacional de Colombia.

El proyecto se estructuró a partir de dos consideraciones: i) la formulación de las políticas públicas ambientales requiere de información para tener un soporte empírico confiable, y ii) la elaboración del Sistema de Cuentas Satélites de Ambiente (SCSA) ${ }^{1}$ busca aportar y servir de guía para la evaluación de

1 En Colombia el Sistema de Cuentas Nacionales en lo ambiental, según lo establecido en DANE (1993; 2003) se encuentra conformado por dos elementos: i) el Marco o Sistema Central, y ii) el Sistema de Cuentas Nacionales Ambientales, también conocido como Sistema de Cuentas Satélites de Ambiente. 
la política pública ambiental. De ahí se trazó como objetivo principal de la investigación diagnosticar la pertinencia de la regulación del Sistema de Cuentas Nacionales Ambientales (SCNA) en la formulación de la política pública ambiental en Colombia entre 1995-2010, para lo cual la investigación se estructuró en tres etapas.

En la etapa I se evaluó la información generada por el SCNA en relación con su objetivo, en la etapa II se analizó cómo aporta la información del SCNA a la regulación pública ambiental y por último en la etapa III se identificó en qué medida se ha usado la información del SCNA en la elaboración de regulación pública ambiental, y el nivel de aporte de dicha información a las necesidades de la política pública ambiental.

Para dar cumplimiento al objetivo se realizó una investigación cualitativa - analítica soportada en un estudio crítico de la literatura encontrada. Efectuando en primera medida un abordaje teórico sobre el concepto de lo público, el papel de la política y del Estado en la definición de las prioridades del país para responder al interés común. En segundo lugar, se hace una revisión de los Planes Nacionales de Desarrollo (PND) de 1994 a 2010, revisando las prioridades ambientales establecidas por cada gobierno, los aportes y deficiencias que presentan en lo ambiental. Posteriormente, se muestra un examen de la información publicada por el Departamento Administrativo Nacional de Estadística (DANE) en su página web sobre las cuentas satélites de ambiente. Finalmente, se retoman las prioridades ambientales de los PND, los aportes y vacíos de la información emitida por el DANE, y se confronta con la necesidad de entender las realidades del país como parte del proceso de construcción de lo público, para este caso a partir de la información del SCSA.

Los referentes teóricos de cada tema son: sobre lo público y el Estado, Weber (1969), Daly \& Cobb (1993), Uricoechea (2001), Molina (2003), Bautista (2003), Sandoval (2003) y Giraldo (2003); para Cuentas Nacionales Ambientales se tuvo como refe- rentes Naciones Unidas (2002), Naciones Unidas et al. (20092), DANE (1993, 2003), Montoya (2001), Isa, Ortúzar \& Quiroga (2005), Talero (2007) y Murcia (2009); por último en el ámbito de política pública ambiental se revisaron a autores como Tobasura (2006), Fonseca, Rincón \& Valderrama (1997), Puente (2008), Moreno (2010), y Rodríguez (2010), entre los más importantes.

En debates sobre el concepto de ambiente, se ha revaluado el uso del término medio ambiente, usado por autores citados en el texto. Por ello entendemos que el ambiente "implica una concepción dinámica, cuyos elementos básicos son una población humana (...), un entorno geográfico, con elementos naturales (...) y una infinita gama de interacciones entre ambos elementos. Para completar el concepto hay que considerar, además, un espacio y tiempo determinados, en los cuales se manifiestan los efectos de estas interacciones" (Tréllez \& Quiroz, 1995; citado en Tréllez, 2002, 9-10).

Esta investigación intentó aportar un análisis del SCNA de Colombia, que dé luces para evaluar en qué medida la información suministrada por dicho sistema aporta y es utilizada para la formulación de políticas públicas ambientales de acuerdo a las prioridades ambientales del país.

\section{Una reflexión de lo público como referente para el aporte de las Cuentas Satélites deAmbiente parala formulación de política pública}

El análisis del SCSA en Colombia se realizó teniendo en cuenta los objetivos que debe cumplir la información de estas cuentas. Retomando propuestas del Sistema de Contabilidad Ambiental y Económica Integrada - SCAEI:

"El proceso de contabilidad genera un cúmulo de información que puede facilitar la formulación de políticas económicas y sobre el medio ambiente y utilizarse para evaluar el funcionamiento de la economía, reformar la política económica y evaluar la

2 La versión 2008 del Sistema de Cuentas Nacionales de las Naciones Unidas (SCN 2008) fue publicada hasta 2009. Por ello, las citaciones de Naciones Unidas et al. (2009) que aparecen en el presente documento hacen referencia al SCN 2008. 
eficacia de las reformas. Puede también servir para identificar problemas y prioridades en la esfera del medio ambiente, determinar los puntos de presión, diseñar políticas sobre el medio ambiente, elaborar disposiciones internacionales para controlar la contaminación transfronteriza y evaluar los efectos de las políticas de ordenación ambiental" (Naciones Unidas, 2002, 429).

Estos objetivos también se contemplan para el caso de Colombia, donde se busca "servir de guía para la evaluación de las políticas ambientales nacionales, como instrumento que sintetiza el monto y la dirección del gasto ambiental, conocer la relación entre producción y contaminación sectorial, e identificar los agentes que intervienen en la conservación del medio ambiente" (DANE, 2003, 21).

En este sentido, la elaboración de cuentas satélites de ambiente busca aportar a la política pública brindando información como soporte para la toma de decisiones. Por ello es importante tener una claridad sobre lo público, como referente para entender cómo se realizaron los análisis y se formularon las críticas que buscan aportar a la construcción del SCSA y a una revisión de la pertinencia de los esfuerzos que se están realizando en el DANE para este tema.

\subsection{Una comprensión de lo público como referente de análisis}

Generalmente cada persona forma su propia noción de lo que significa lo público mediada tanto por sus vivencias como por su reflexión sobre el tema. En este caso retomamos los conceptos que dieron origen a la constitución de lo público en Grecia.

De acuerdo a (Molina, 2003) esos conceptos son la politike, enmarcado en los asuntos del gobierno de la comunidad, y la politeia los asuntos de la vida en comunidad. A ello se suman los ideales que posibilitaron el surgimiento de lo público en esta sociedad, el amor al prójimo más allá de los círculos de sangre, etnia y raza, el surgimiento de la ciudad occidental y el nacimiento del mercado capitalista (Uricoechea, 2001).

A través del tiempo la noción de lo público se ha ido reconfigurando, en los siglos XVII y XVIII lo pú- blico mantenía un carácter normativo, existía para la sociedad burguesa, y excluía a quienes no eran considerados como ciudadanos. Weber $(1969,95)$ se refiere a la conformación de comunidades que se dicen libres "no en el sentido de estar libres de toda dominación violenta, sino en el de que en ellas no existía como fuente única de autoridad el poder del príncipe”. En el siglo XX con las luchas obreras se empieza a incluir otros sectores de la población en la aplicación de las políticas públicas, quedando restringida la participación en la definición del Estado y por ende la formulación de políticas públicas solo a quienes logren el estatus de ciudadanos.

Estos cambios sociales incidieron también sobre la noción de individuo "definido en términos racionales por oposición al individuo del mundo fundado en el carisma, la tradición y la autoridad" (Uricoechea, $2001,51)$ por uno egoísta que deviene de la sociedad burguesa. Esto tiene implicaciones sobre la formulación de las políticas públicas, porque la sociedad pasa de considerarse como comunidad a la suma de individuos, y a tomar como referente de acción el mercado, donde los protagonistas son los individuos, quienes tienen libertad de elegir (Bautista, 2003), el interés público de la sociedad se reduce a lo expresado por el mercado.

Al respecto Georgescu-Roegen (1996) quien elabora una crítica a la manera clásica de pensar la economía, recuerda a Marx y Marshall, quienes planteaban que la razón burguesa no es válida para todas las sociedades, como ha sido concebido por la economía. Por su parte Daly \& Cobb (1993, 5354) reivindican el carácter comunitario de las sociedades, al afirmar que "algo análogo a la tendencia del mercado a desgastar sus propios fundamentos competitivos es el efecto corrosivo del interés individualista sobre el contexto moral que tiene la comunidad. Por mucho que este impulsado por el interés propio, el mercado depende todavía absolutamente de una comunidad que comparta valores tales como los de la honestidad, la libertad, la iniciativa, el ahorro."

El interés público se asimila con el de la sociedad pero es necesario salvaguardarlo, para lo cual existe la figura del Estado. Quienes han tratado el tema de 
lo público resaltan que hay una tendencia a asimilar que lo público se refiere únicamente al Estado, pero es necesario aclarar que "lo estatal es un medio y un momento para hacer posible lo público" (Molina, 2003, 50). El momento está relacionado con el nacimiento del capitalismo en el que el papel del Estado se finca en proteger los negocios y la propiedad privada "de garantizar un orden político y financiero que permita el desarrollo del mercado" (Giraldo, 2003, 15) constituyendo la dimensión política del Estado.

De esta manera entendemos que lo público esta agenciado por el Estado, institución que debe salvaguardar el interés común, no limitado a las tendencias del mercado, sino como una expresión de los intereses que se desprenden de lo personal y comunitario.

\subsection{El papel del Estado en la definición de lo público: contexto de reformas}

Como se mencionó en el apartado anterior el interés público se asimila con el de la sociedad, pero es necesario salvaguardarlo, para lo cual existe la figura del Estado. A esto se le conoce como la dimensión política del Estado. Giraldo (2003) plantea que también existe una dimensión productiva del Estado, que consiste en la producción de bienes y servicios consumidos por la sociedad, que son necesarios para la reproducción de capital y su acumulación, por ejemplo la infraestructura que es de uso público aunque sus intereses más prioritarios se encuentren en el seno de los mercados, para la circulación de las mercancías.

Esta dimensión política del Estado va de la mano con el papel de este en lo productivo, pues "a pesar de la privatización, la producción de estos bienes y servicios es de naturaleza colectiva, su utilización afecta los intereses comunes de la sociedad, y su provisión no se puede hacer en un mercado de libre competencia" (Giraldo, 2003, 33). Que la producción este bajo el control de lo privado no le quita su carácter público porque interesa a la colectividad asuntos como la calidad de alimentos, la forma como esto afecta a la salud pública y actualmente temas ambientales como el cambio climático, la seguridad alimentaria, la desertificación, la biodiversidad, entre otros.
Entonces el interés público, la manera como se asume por el Estado, las políticas públicas que se derivan de esto y la forma como se articulan con lo productivo, se inscriben en lo político porque implica tomar decisiones en esferas económicas, sociales y ambientales, que afectan la vida de las personas.

Ahora se pasará a revisar con celeridad algunas configuraciones históricas que dan cuenta de las características del Estado actual colombiano y cómo se articulan con la globalización, Giraldo (2003) hace referencia al monopolio de poder en manos de una clase media fuerte que incursionó en la economía formal, mientras la otra parte de la población velaba por satisfacer sus necesidades, apartando de su cotidianidad el control social, este fue el periodo de Industrialización por Sustitución de Importaciones. Esa situación derivó en un bipartidismo excluyente, sumado a la dependencia económica frente al movimiento mundial del capital, lo cual incidió en la regulación estatal de orden social, dentro de una estructura política marcada por el clientelismo, la corrupción y el tecnocratismo (Sandoval, 2003). Aspectos que definen la manera como se han generado problemáticas sociales y económicas en Colombia.

A partir de las reformas que llegaron con el Consenso de Washington (CW) se impulsa la privatización y se intenta sacar este proceso del debate político, lo cual se logra al utilizar criterios de mercado como la eficiencia, negando que los servicios públicos al fin de cuentas son un derecho social y se inscriben en la esfera de lo público. Sin reflexionar sobre el hecho de que "los intereses colectivos, no pueden estar por fuera del proceso político no importa que la gestión sea privada" (Giraldo, 2003, 33). En la medida que los temas ambientales también se insertan en el debate político, es importante concebir las políticas ambientales como parte de la configuración de lo público.

Ahora bien, después de haber realizado un análisis sobre lo público y la importancia que tienen en la definición de este, tanto la política como el Estado, a continuación se revisará la política ambiental en Colombia entre 1994 y 2010 con el fin de establecer si dicha política pública contribuyó o no a la salvaguarda de lo público. 


\subsection{El contexto de la política ambiental en Colombia}

A nivel internacional el referente más importante que pone su atención en las problemáticas ambientales, vinculadas al desarrollo fue la Cumbre de la Tierra que tuvo lugar en Rio de Janeiro en 1992. De esta cumbre emerge como referente principal La Agenda 21.

En Colombia el Código de los Recursos Naturales Renovables y de Protección del Medio Ambiente es el primer referente jurídico de regulación de la gestión ambiental y de manejo de recursos naturales. La Ley 99 de 1993 se deriva de la Constitución Verde (o Constitución de 1991), con esta ley se crearon el Ministerio del Medio Ambiente y el Sistema Nacional Ambiental (SINA) pero "a la vez que favorece la creación y asignación de funciones específicas a las instancias que conforman el SINA, descuida un aspecto esencial como es la conexión $y$ armonización entre las diferentes instituciones y sobre todo la relación biunívoca entre pobreza y medio ambiente" (Fonseca, Rincón \& Valderrama, 1997, 149).

Según lo señala Moreno (2010), el Estado en Colombia ha reformado sus instituciones, buscando que estas se ajusten a la nueva fase de acumulación capitalista donde la naturaleza representa el nuevo nicho de agregación de valor capitalista, dejando de lado su rol como garante de la distribución equitativa de los bienes comunes sobre la base de justicia social y ambiental, pues "en Colombia al contrario de que se cumpla este rol del Estado, él mismo es base de la inequitativa distribución de los bienes de la naturaleza y causa de los conflictos socio-ambientales" (Moreno, 2010, 293).

Al respecto se esbozaran algunas consideraciones a partir de una revisión de los PND en su componente ambiental y de las políticas ambientales en los diferentes periodos de gobierno entre 1994 y 2010, y se contrastaran con algunas reflexiones sobre los temas ambientales en Colombia, como un acercamiento a la manera como el Estado colombiano ha asumido lo ambiental.

\subsection{Prioridades de la política ambiental en los Planes Nacionales de Desarrollo entre 1994 y 2010}

El PND es el instrumento en el que se definen las políticas de cada periodo de gobierno presidencial, a partir de allí se puede conocer el enfoque para los temas ambientales y su relación con los demás temas de política. Lo ambiental se insertó en Colombia a partir de la Constitución Política de 1991, sin embargo de acuerdo con los propósitos de la investigación se revisan y comparan cuatro periodos de gobierno recogiendo críticas ya realizadas por otros autores y unas que surgen de esta investigación. Los periodos de gobierno de revisión fueron:

- "El salto social, es tiempo de la gente" (19941998) de Ernesto Samper Pizano

- "Camino para construir la paz" (1998-2002) de Andrés Pastrana Arango

- "Hacia un Estado comunitario" (2002-2006) de Álvaro Uribe Vélez

- "Estado comunitario: desarrollo para todos" (2006-2010) de Álvaro Uribe Vélez

Además se realizaron algunas anotaciones relacionadas con el periodo de gobierno de Cesar Gaviria Trujillo "La revolución pacífica" (1991-1994). Para mirar los periodos de gobierno vale la pena retomar a Moreno (2010) quien identifica en la política ambiental de Colombia dos periodos y sus características principales, el de creación y consolidación de la institucionalidad ambiental (entre 1991 y 2002) y el modelo productivista en el que hay retroceso de lo ambiental (2002 a 2009). En la Ilustracion1 se puede apreciar en cuál de los dos periodos (Institucionalidad ambiental o productivista) se encuentra cada uno de los gobiernos revisados.

El periodo de consolidación de la institucionalidad ambiental, el cual corresponde principalmente al periodo comprendido entre 1991 y 2002, presenta las siguientes características. En "La revolución pacífica" (1991-1994) fue el periodo en el que se creó el SINA a partir de la Constitución Política de Colombia. En el "Salto Social"(1994-1998) se inserta el concepto de desarrollo humano sostenible, mientras 
Ilustración 1. Periodos de política ambiental en Colombia $^{3}$

\begin{tabular}{|c|c|c|}
\hline \multicolumn{3}{|c|}{ Cuentas Satélites de Colombia } \\
\hline \multicolumn{3}{|c|}{$\begin{array}{l}\text { "Tienen como finalidad cuantificar los fenómenos de deterioro y mejoramiento del medio } \\
\text { ambiente, el estado de los recursos naturales y los gastos destinados al medio ambiente. Se } \\
\text { caracterizan por inscribirse bajo el marco de las cuentas nacionales. Se diferencian de este en } \\
\text { cuanto a que amplian el concepto de patrimonio naturarl" (DANE, 2003, pp. 3). Estas cuentas } \\
\text { satélites se encuentran conformadas por tres componentes: }\end{array}$} \\
\hline $\begin{array}{l}\text { Cuentas ambientales de } \\
\text { los recursos naturales en } \\
\text { términos físicos }\end{array}$ & $\begin{array}{l}\text { Cuentas ambientales en } \\
\text { términos monetarios }\end{array}$ & $\begin{array}{l}\text { Cuentas de sostenibilidad } \\
\text { del ambiente }\end{array}$ \\
\hline $\begin{array}{l}\text { Contemplan las } \\
\text { modificaciones en los stock } \\
\text { de los activos naturales no } \\
\text { producidos tanto económicos } \\
\text { (tierra, bosque natural, } \\
\text { recurso hídrico y los activos } \\
\text { del subsuelolo como no } \\
\text { económicos (las reservas } \\
\text { hipotéticas del subuselo, } \\
\text { animales silvestres, los } \\
\text { peces, los mares y océanos } \\
\text { y el aire) }\end{array}$ & 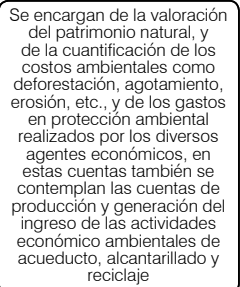 & $\begin{array}{l}\text { Relacionadas con los } \\
\text { gastos de repercusión }\end{array}$ \\
\hline
\end{tabular}

con el Proyecto Colectivo Ambiental entre 1998 y 2002, se introduce el concepto de ecosistemas estratégicos como enfoque eco-sistémico para la protección ambiental (Moreno, 2010).

En la opinión de Mance (2008, citado en Rodríguez, 2010) se dio una consolidación restringida del Ministerio de Ambiente en los gobiernos "La revolución pacífica" y "El salto social", presentándose "algunos retrocesos en la normatividad al lado de sustantivos avances en la gestión (...) se reformó el Código de Minas, que les restó al Minambiente y a las Corporaciones Autónomas Regionales competencias en el campo del otorgamiento de las licencias ambientales en el sector minero (...) comenzaron a declinar las asignaciones del presupuesto nacional para la gestión ambiental" (Rodríguez, 2010, 24). Veamos en más detalle aspectos de la política ambiental de estos dos gobiernos.

Con "El Salto social" "se inaugura un concepto muy relevante en la política ambiental, el concepto de Desarrollo Humano Sostenible" (Moreno, 2010, 296). Del mismo modo, también se fomentó el desarrollo por medio de la protección ambiental y de la educación con el fin de enriquecer el capital social con oportunidades de producción, pero da prioridad a los instrumentos económicos (Tobasura, 2006).
Como prioridades están los ecosistemas estratégicos por ser vitales para la economía o críticos para la conservación de la biodiversidad. Para este último elemento se crean los Parques Nacionales Naturales (PNN), las reservas privadas, investigación en biotecnología, reglamentación de acceso a recursos genéticos y propiedad intelectual (Rodríguez, 1995). Así, desde el gobierno Samper se plantearon las reservas naturales que actualmente ya están definidas y delimitadas, lo mismo sucede con los resguardos indígenas y propiedad colectiva de afros, que cumplen la misma función con la diferencia que son gestionadas por sus habitantes y no por especialistas. Como se verá en el siguiente apartado, ninguna de estas figuras territoriales, ni la biodiversidad como un patrimonio que tiene que ser cuidado, se refleja en el SCSA de Colombia.

El PND "El Salto Social" presentaba vacíos por la ausencia de programas y metas para los temas de salud, educación, infraestructura para la productividad, políticas de modernización industrial y comercio exterior, temas que posteriormente fueron subsanados por el Consejo Nacional de Política Económica y Social a través del (CONPES) (Rodríguez, 1995). De hecho los comentarios sobre la política ambiental de Samper resaltan el énfasis en la educación ambiental (Tobasura, 2006; Rodríguez, 1995, 2010).

De otro lado en el PND "Camino para construir la paz" (1998-2002), se establece trabajar conjuntamente para obtener resultados globales, igualmente se hace un llamado a la conciencia ambiental para que sea incluida en la cultura y se entienda las limitaciones naturales de los individuos para vivir en tolerancia y en paz. Se constituye al agua como eje articulador de la política, educación y concienciación ambiental, y se planteaba la protección de áreas prioritarias en ecoregiones estratégicas, desarrollo regional y sectorial sostenible (Tobasura, 2006).

Como se mencionó este PND planteaba programas para agua, políticas para los temas de biodiversidad, bosques. Dentro de las estrategias establecía un "esquema descentralizado, participativo y democrático

3 Fuente: Elaboración propia basada en Moreno (2010). 
(y) se parte del principio de que el medio ambiente está afectado por los distintos sectores económicos y su tratamiento tiene una concreción en lo regional y local" (Tobasura, 2006, 14), por eso resulta importante emitir información en el SCSA por regiones y más si se trata de formulación de políticas públicas ambientales.

En el caso del PND "Camino para construir la paz", no es mucho lo que se hizo institucionalmente pero se mantuvo lo que se había construido desde los dos periodos de gobierno anteriores. En este PND se toma en cuenta el tema ambiental como una de las prioridades para la construcción de la paz.

Para ello el PND planteaba "se hará un esfuerzo significativo por integrar y unificar la información básica y aplicada disponible, escrita, estadística y cartográfica, entre el sector público, privado y comunitario, (...) En este sentido, la política privilegiará la consolidación del Sistema de información ambiental para Colombia" (PND, 1999, 367). Como se denota se hablaba de la importancia de la información pero no como un complemento del Sistema de Cuentas Nacionales sino como algo más amplio.

Seguido de este gobierno inicia el modelo productivista, el cual abarca los dos periodos de gobierno de Uribe, como lo clasifica Moreno (2010), debido al cambio de rumbo que se dio y el cual se caracterizó principalmente por la desregulación ambiental, la reprimarización de la economía y el privilegio a la inversión extranjera.

El PND "Hacia un estado comunitario" (2002-2006), en comparación con los anteriores PND es el más débil en lo ambiental, su prioridad es la producción frente a lo cual la institucionalidad perdió fuerza y por lo tanto importancia. Su estrategia de sostenibilidad ambiental contemplaba cinco programas: (i) conservación y uso sostenible de bienes y servicios ambientales; (ii) Manejo integral del agua; (iii) generación de ingresos y empleo verde; (iv) sostenibilidad ambiental de la producción nacional; y $(\mathrm{v})$ planificación y administración del medio ambiente (Tobasura, 2006). En el de conservación y uso sostenible de bienes y servicios ambientales se buscaba el mantenimiento de la base natural, para esto último resulta importante el
SCSA que tiene como uno de sus objetivos cuantificar en términos físicos la base natural.

Como bien expone (Rodríguez, 2007), la política ambiental de este gobierno se caracterizó por el debilitamiento institucional y por tanto de la política ambiental, en función de "sacrificar la protección del medio ambiente a los objetivos del crecimiento económico de corto plazo", disminución de recursos presupuestales en $50 \%$, y perdida de jerarquía en el PND (Rodríguez, 2007). En los temas ambientales se abordó los relativos al manejo del agua, el manejo de cuencas, conservación y fomento de la biotecnología, la biodiversidad y gestión de bioseguridad, estos últimos cuatro relacionados con el Convenio de Biodiversidad.

La política ambiental de Uribe a simple vista puede parecer atractiva, sin embargo es necesario revisarla con cuidado, ya que tiene muchos cuestionamientos. Puente (2008) menciona los riesgos de esta política ambiental, quien señala que según Guhl son medidas regresivas para atraer la inversión extranjera, de lo cual da cuenta la flexibilización en los procesos para otorgar licencias ambientales, sobre las normas de contaminación del aire, ley del agua y la ley de bosques, y qué decir de la fumigación en parques y la intervención en los páramos. A continuación se presenta en la tabla 1 los riesgos identificados por Puente (2008).

La tabla 1 ilustra algunas de las implicaciones ambientales tanto de corte ecológico como social que se derivan de decisiones políticas, concretadas en la legislación y la política pública, de allí la importancia de evaluar el contexto nacional, como punto de partida para el análisis crítico sobre los avances de la generación de información del SCSA en Colombia.

Según Tobasura $(2006,17)$ para el PND $(2003)$ "el legado de treinta y cinco años que ha construido el país, en este gobierno se está perdiendo, o por lo menos se ha frenado, con consecuencias nefastas para la conservación de la base natural que es el soporte del desarrollo en el nivel nacional y la pérdida de protagonismo del país en la esfera internacional". En el caso del SCSA debemos hacer una reflexión frente a lo que se necesita conocer en los temas prioritarios para Co- 
Tabla 1. Riesgos de la política ambiental del gobierno de Uribe ${ }^{4}$

\begin{tabular}{|l|l|l|}
\hline \multicolumn{1}{|c|}{ Tema ambiental } & \multicolumn{1}{|c|}{ Política pública } & \multicolumn{1}{c|}{ Riesgo } \\
\hline $\begin{array}{l}\text { Fumigación en Parques Nacionales } \\
\text { Naturales }\end{array}$ & Fumigación de glifosato, permitido por Colombia. & $\begin{array}{l}\text { "Malformaciones, aumento en los abortos, nacimien- } \\
\text { tos prematuros y problemas de reproducción" (Puente, } \\
2008,519)\end{array}$ \\
\hline Transgénicos de Monsanto & $\begin{array}{l}\text { Decreto } 4225 \text { del } 2005 \text { sobre el tema de biotecnología del } \\
\text { convenio de biodiversidad. }\end{array}$ & $\begin{array}{l}\text { Hay dudas del impacto de los transgénicos sobre la } \\
\text { fauna y ya se conocen casos de contaminación a culti- } \\
\text { vos no transgénicos. }\end{array}$ \\
\hline Caída de la ley forestal & $\begin{array}{l}\text { Ley forestal expedida en 2006 "eliminaba las licencias am- } \\
\text { bientales para cierto tipo de proyectos forestales" (Puente, } \\
2008,520)\end{array}$ & $\begin{array}{l}\text { Según Mayr citado por Puente (2008, 520): "no solo } \\
\text { amenazaba los bosques naturales y sus servicios am- } \\
\text { bientales, sino que violaba los derechos constitucio- } \\
\text { nales de los pueblos indígenas y afrodescendientes". }\end{array}$ \\
\hline $\begin{array}{l}\text { Retroceso en gestión de residuos } \\
\text { peligrosos }\end{array}$ & $\begin{array}{l}\text { La falla de la Constitución del 91 al prohibir solamente la } \\
\text { entrada de residuos nucleares y tóxicos, se mejoró con la } \\
\text { resolución 189 de 1994 que prohibió todos los peligrosos. } \\
\text { El gobierno Uribe lo derogó, dejando en manos de acuerdos } \\
\text { como el Tratado de Libre Comercio- TLC con Estados Unidos, } \\
\text { la entrada de residuos diferentes a los tóxicos y nucleares. }\end{array}$ & $\begin{array}{l}\text { Producen diferentes efectos dañinos para la salud y el } \\
\text { ambiente. }\end{array}$ \\
\hline
\end{tabular}

lombia, y compararlo con la información que se ha emitido, para mirar a qué intereses responde.

El segundo mandato de Uribe, en su PND "Estado comunitario: desarrollo para todos" (2006-2010), inicialmente se descuidó en gran medida lo ambiental. Por influencia del Consejo Nacional de Planeación (CNP), el PND insertó la sostenibilidad ambiental con una visión ecosistémica, poniendo mayor énfasis en la protección del ambiente marino, políticas específicas para regiones amazónica y pacífica, $e$ inserción de criterios ambientales en las políticas sectoriales, lo cual fue visto como una respuesta positiva del gobierno frente a lo ambiental (Rodríguez, 2007).

El texto final estableció como componentes y estrategias: planificación ambiental en la gestión territorial, gestión integrada del recurso hídrico, conocimiento, conservación y uso sostenible de la biodiversidad, promoción de procesos productivos competitivos y sostenibles, prevención y control de la degradación ambiental, fortalecimiento del SINA para la gobernabilidad ambiental (PND, 2007).
En lo que nos interesa del SCSA, este es el único PND que pone explícitamente como una tarea, la generación de esta información y el trabajo conjunto del IDEAM (Instituto de Hidrología, Meteorología y Estudios Ambientales), del MAVDT (Ministerio de Ambiente, vivienda y Desarrollo Territorial) y del DANE, "Bajo la coordinación del IDEAM, se establecerá el registro de fuentes generadoras de datos ambientales con el fin de disponer de información ambiental de mayor calidad, oportunidad y cobertura. Por otra parte, conjuntamente entre el MAVDT y el DANE, se promoverá una estrategia para la estructuración de las cuentas ambientales nacionales, como un instrumento de planificación y toma de decisiones; este proceso requerirá la priorización de los temas que deben contener y la definición de los lineamientos metodológicos para su construcción" (PND, 2007, 368). En torno a esto, se verá cuáles son las prioridades ambientales que se definieron en las fichas metodológicas, y cómo se articula con el énfasis extractivista y minero de este gobierno.

Vale la pena aclarar que como resultado del primer mandato de Uribe, mediante la Ley 790 de 2002 y el Decreto Ley 216 de 2003, al Ministerio del Medio

\footnotetext{
4 Fuente: Elaboración propia basado en Puente (2008).
} 
Ambiente se le asignó las funciones de vivienda y desarrollo territorial, por lo cual la denominación de este Ministerio se modificó, dando lugar a la creación del Ministerio de Ambiente, Vivienda y Desarrollo Territorial. En complemento, en el gobierno de Santos, mediante la Ley 1444 de Mayo de 2011, se decretó la escisión del Ministerio de Ambiente, Vivienda y Desarrollo Territorial en dos carteras, una encargada de las funciones ambientales y otra que tenga a cargo los temas sectoriales de vivienda y saneamiento básico. Se crea de esta forma, el Ministerio de Ambiente y Desarrollo Sostenible (MADS), el cual estará encargado de la gestión ambiental del Estado (MADS, 2012).

Siguiendo con Moreno (2010), los dos periodos de gobierno de Uribe, se caracterizaron por su retorno al paradigma "productivista" - desarrollista pero anclado a la globalización de las transnacionales, perfilado como un régimen propulsor del latifundio. El modelo económico se direccionó hacia la reprimarización de la economía basada en la oferta de mano de obra, tierras y recursos naturales baratos, como ventaja competitiva. Como consecuencias "implica no sólo los impactos ambientales in situ de las explotaciones, sino procesos de intercambio desigual y acumulación de pasivos ambientales" (Moreno, 2010, 297).
En general, la política ambiental ha sido tenida en cuenta en los PND que van de 1991 hasta 2006, y ponen atención a la conservación de espacios naturales, el desarrollo sostenible de las regiones, mejorar la calidad de vida de los individuos y alcanzar la paz (Tobasura, 2006). En el último PND de estudio como ya se mencionó, la apuesta por lo ambiental se insertó por las recomendaciones del CNP, pero no hacían parte inicial de la política pública del gobierno.

La concreción de la política ambiental en términos de leyes y lineamientos de política de los gobiernos desde 1994 a 2010 se resume en la tabla 2.

En contraste con los PND, este cuadro da cuenta de las prioridades ambientales de cada gobierno, las cuales son diferentes en cada periodo. En "El salto social" no se avanzó en las políticas por sectores, en "Camino para construir la paz" proponía el agua como eje articulador de la política pública pero no se evidenció, tampoco se generaron ni leyes ni políticas para la biodiversidad. En "Hacia un Estado comunitario" se avanzó en las políticas, bajo la lógica ya expuesta por Moreno (2010), frente a lo cual se adelantó la ley forestal que tenía tantos reparos y la cual en 2007 fue declarada inexequible por la Corte

Tabla 2. Leyes y políticas elaboradas en los gobiernos desde 1994 a $2010^{5}$

\begin{tabular}{|c|c|c|c|c|}
\hline \multicolumn{5}{|c|}{ Regulación y política ambiental } \\
\hline $\begin{array}{l}\text { Instrumento de regu- } \\
\text { lación /PND }\end{array}$ & Salto social & Camino para construir la paz & Hacia un Estado comunitario & $\begin{array}{l}\text { Estado comunitario: desarro- } \\
\text { llo para todos }\end{array}$ \\
\hline Leyes & $\begin{array}{l}14 \text { leyes: en temas de re- } \\
\text { curso hídrico, diversidad } \\
\text { biológica, capa de ozono, } \\
\text { tributos, residuos, flora, } \\
\text { fauna, humedales, gestión } \\
\text { ambiental urbana, residuos y } \\
\text { desarrollo territorial }\end{array}$ & $\begin{array}{l}10 \text { leyes en temas de flora, } \\
\text { minería, suelo, capa de ozo- } \\
\text { no, fauna, cambio climático }\end{array}$ & $\begin{array}{l}9 \text { leyes en temas de calidad } \\
\text { del aire, gestión ambiental } \\
\text { urbana, fauna, diversidad } \\
\text { biológica, biocombustibles, } \\
\text { flora, capa de ozono, y áreas } \\
\text { de conservación y protec- } \\
\text { ción }\end{array}$ & $\begin{array}{l}8 \text { leyes en temas de gestión } \\
\text { ambiental urbana, riesgo, } \\
\text { modificación a la ley 99, re- } \\
\text { siduos, comparendo ambien- } \\
\text { tal (instrumento de política) y } \\
\text { minería }\end{array}$ \\
\hline $\begin{array}{l}\text { Formulación de po- } \\
\text { líticas }\end{array}$ & $\begin{array}{l}\text { Políticas de bosques, pro- } \\
\text { ducción limpia, residuos y } \\
\text { biodiversidad }\end{array}$ & $\begin{array}{l}\text { Políticas de gestión ambien- } \\
\text { tal, ordenamiento territorial, } \\
\text { y recursos marinos y zonas } \\
\text { costeras }\end{array}$ & $\begin{array}{l}\text { Política para humedales y } \\
\text { residuos }\end{array}$ & $\begin{array}{l}\text { Políticas de gestión ambien- } \\
\text { tal urbana, calidad del aire, } \\
\text { recursos marinos, y zonas } \\
\text { costeras y recurso hídrico }\end{array}$ \\
\hline
\end{tabular}

5 Fuente: Elaboración propia basado en la información de la página web del Ministerio de Ambiente, Vivienda y Desarrollo Territorial (2011). 
Constitucional por no haber acudido al mecanismo de la consulta previa. Finalmente en "Estado comunitario: desarrollo para todos", no hubo expedición de leyes ni formulación de políticas para el tema de biodiversidad, y en vez de fortalecer el SINA, se llevó a un debilitamiento, por disminución presupuestal, y perdida de jerarquía es la estructura de la rama ejecutiva del Estado.

El SCSA empezó a generar información a partir del primer periodo de gobierno de Uribe, pero la revisión sobre los demás PND no ha sido en vano, pues sería ciego analizar las cuentas sin tener en cuenta el contexto y el desarrollo que ha tenido en los diferentes gobiernos.

La política ambiental contenida en los PND de los gobiernos entre 1994 y 2010 plantea prioridades ambientales, principalmente de protección ambiental, en diversas áreas coincidiendo en el manejo de la biodiversidad. El acceso a la información de manera pública, como fuente de toma de decisiones hizo parte de dos PND, "Camino para construir la paz" y "Estado comunitario: desarrollo para todos". Solo en este último PND se menciona como prioridad la elaboración de cuentas nacionales ambientales como insumo para la formulación de políticas públicas.

\section{Avances y vacíos de la información del Sistema de Cuentas Satélites de Am- biente en Colombia}

Como se vio en el apartado anterior las cuentas satélites de ambiente en Colombia se plasmaron explícitamente como parte del PND solo hasta el gobierno de Uribe (2002-2006), de ello dan cuenta los esfuerzos en la información que se ha emitido hasta el momento. La información que se analizó, ha sido aquella emitida por el DANE, fichas metodológicas, boletines de prensa y la información contenida en su página web.

Hay que evaluar el contexto y el alcance de las cuentas satélites de ambiente, pues estas son elaboradas por el DANE y aunque el propósito es aportar a la formulación de política pública, de hecho tal como aparece en la web del DANE "Las Cuentas Económico-Ambientales, a través de cuadros monetarios y físicos, permiten describir las interrelaciones existentes entre la economía y el medio ambiente, con el fin de apoyar la formulación de políticas públicas. Para ello, cuantifica los fenómenos de deterioro y mejoramiento del medio ambiente; los gastos destinados a la conservación, mitigación, protección del medio ambiente $\mathrm{y}$, a su vez, determina la variación en el estado de los recursos naturales" (DANE, 2011), también pueden aportar al Sistema de Información Ambiental de Colombia (SIAC).

\subsection{Origen y situación del Sistema de Cuentas Satélites de Ambiente}

En primer lugar "el Sistema de Cuentas Nacionales tiene sus bases y orígenes hace aproximadamente medio siglo, midiendo el crecimiento de la economía en términos del Producto Interno Bruto (PIB), entendiendo esto como el valor de todos los bienes y servicios finales que se producen en la economía, valorados a precio de mercado" (Torres et al., 2001, 68). El PIB es comúnmente utilizado para medir el desempeño (crecimiento) de la economía y el bienestar social de un país, cuando se transforma en mediciones de tipo per cápita, o de ingreso nacional, o cuando se integra o combina con otros indicadores simples para generar otro tipo de indicadores más complejos como el indicador de desarrollo humano, el GINI, entre otros de índole social. A primera vista, existe la tendencia a creer que incrementos en este indicador se encuentran relacionados con aumentos en el crecimiento económico de una nación y en el bienestar de la sociedad. No obstante, el uso del PIB como indicador de bienestar social se puede catalogar como erróneo, esto debido a que en primera medida, los aumentos en el crecimiento económico de un país no necesariamente se encuentran relacionados con incrementos en el bienestar social de la población. Montoya $(2001,187)$ señala que "las evidencias empíricas que permiten relacionar satisfactoriamente el PIB con indicadores de bienestar construidos a partir de él no son suficientemente convincentes", porque para ello se depende de una política equitativa de distribución de ese crecimiento sobre la población participante.

En segunda medida, como señalan Tinbergen \& Hueting (1994) las políticas económicas basadas en 
indicadores que dan prioridad el crecimiento del ingreso nacional (resultado del ajuste que se le hace al PIB descontando las Rentas Netas de los Factores Externos), privilegian el aumento de la producción de bienes y servicios en una economía, sin contemplar la destrucción ambiental, que es provocada por el desarrollo de las actividades productivas.

Así pues, el PIB "presenta múltiples cuestionamientos en la medida en que da prioridad al crecimiento económico y en tanto sus mediciones no dan cuenta de un verdadero bienestar (solo contempla el bienestar material, no habla de calidad de vida) y de la sostenibilidad de una economía, además no incorporan el uso de los recursos naturales derivado de los procesos de producción. Por lo cual, provee un valor engañoso del crecimiento de un país al mismo tiempo que posibilita el deterioro ambiental al no considerar, como son denominados por la economía ambiental los efectos del proceso económico, las "externalidades negativas", tales como agotamiento de los recursos naturales, los gastos de protección y la degradación ambiental, que surgen como resultado del proceso económico" (Gómez \& Rojas, 2011, 1146).

Ahora bien, el predominio del crecimiento económico, expresado por el PIB, sobre los demás aspectos sociales y ambientales se puso en tela de juicio con la crisis ambiental que se hizo evidente en los años sesenta, esta crisis "vino a cuestionar la racionalidad y los paradigmas teóricos que han impulsado y legitimado el crecimiento económico, negando a la naturaleza" (Leff, 1998, 17).

De ahí que, hacia finales de los años sesentas se comenzaron a producir un conjunto de informes científicos que ponían en evidencia la crisis ambiental de la época. Dentro de los estudios más relevantes al respecto se encuentran el libro "La Primavera Silenciosa" de Rachel Carson publicado en 1962 y el primer informe del Club de Roma titulado "Los Limites al Crecimiento", el cual estuvo a cargo de un grupo de científicos del Instituto Tecnológico de Massachussets y fue publicado en 1972 (Turco, 2012). Dichos trabajos "mostraban tanto la gravedad de ciertos problemas parciales como la situación general, a partir de la proyección, para el futuro de la humanidad, de las tendencias mundiales presentes. Se trató de una alarma con impronta catastrofista que planteaba la situación como extremadamente grave entendiendo que, de no tomarse medidas drásticas de inmediato, se arribaría en algunas décadas a un colapso mundial. La tesis central fue la de los límites físicos al crecimiento, y la propuesta central, la del crecimiento cero, económico y poblacional” (Pierri, 2005, 34).

Ante esta situación se celebraron variadas conferencias mundiales por parte de la Organización de las Naciones Unidas (Dentro de las más importantes se encuentran las celebradas en Estocolmo, Rio de Janeiro y Johannesburgo en los años de 1972, 1992 y 2002 respectivamente), se crearon nuevos organismos como el Programa de las Naciones Unidas para el Medio Ambiente y la Comisión Mundial sobre el Medio Ambiente y el Desarrollo, dentro de los más representativos, y se publicaron variados informes $y$ escritos en los cuales se manifestaba la importancia internacional del ambiente, dentro de los cuales se destaca el Informe Brundtland también conocido como Nuestro Futuro Común, en el cual se utiliza por primera vez el termino desarrollo sostenible. En este Informe se define como desarrollo sostenible aquel que "satisface las necesidades del presente sin comprometer la habilidad de las generaciones futuras para satisfacer sus propias necesidades" (Wced, 1987, citado en El Serafi, 1994, 107). No obstante, existen variadas discusiones frente al uso del concepto, pues este se ha tornado polisémico y ambiguo.

De las conferencias anteriormente mencionadas, la Cumbre de la Tierra realizada en Rio de Janeiro en 1992 se considera un escenario decisivo en términos de la incorporación de lo ambiental en los Sistemas de Cuentas Nacionales. En esta Cumbre se aprobó La Agenda 21, la cual en su capítulo 8 aborda el tema de la integración del medio ambiente y el desarrollo en la adopción de decisiones y señala como uno de los puntos indispensables para lograr dicha integración, la instauración de sistemas de contabilidad ecológica y económica integrada mediante los cuales se amplié "los sistemas actuales de contabilidad económica nacional para dar cabida en ellos a la dimensión ambiental y a la dimensión social, incluyendo por lo menos sistemas de cuentas subsidiarias para los recursos naturales en todos los Estados miembros" (DAES, 1992). 
Resultado de ello, Naciones Unidas, en 1993 publicó una versión provisional de las cuentas satélite del SCAEI. Posteriormente, en el año 2003 publicó una versión actualizada y actualmente viene trabajando en una revisión con miras a su publicación durante el año 2012 (Naciones Unidas et. al, 2009, 534).

Ahora bien, en Colombia, tras lo estipulado en la Agenda 21, se empezó a plantear "la necesidad de disponer de indicadores y otros datos que den cuenta del estado y evolución de los fenómenos ambientales. (Más aún la creciente explotación de los recursos naturales ha justificado) la necesidad de disponer de información básica que permita a las autoridades formular las politicas más adecuadas de protección al medio ambiente y los recursos naturales" (DANE, 2003, 2-3). Con el Sistema de Cuentas Nacionales de 1993 o SCN 1993 (Naciones Unidas et al., 1993) y el SCAEI como estructura contable de referencia para el reconocimiento de la contabilidad de los recursos naturales y las cuentas monetarias ambientales de modo integrado, se buscó satisfacer dichos requerimientos de información.

Pues, mientras el SCN 1993 y 2008 contemplan el reconocimiento de las operaciones económicas, el SCAEI 2003 (Naciones Unidas et al., 2003) funciona como un sistema satélite a éste y como señala Murcia (2009) proporciona una guía para establecer la contribución del ambiente a la economía y si el ambiente está siendo utilizado de manera sostenible. Vale la pena señalar que el SCN 1993 y el SCAEI 2003 sólo proveen "un marco general de orientación, y que es necesario que los diferentes países hagan aportes creativos en la estructuración de sus propios sistemas de contabilidad ambiental. Además, es obvio que cada país debe establecer sus prioridades y definir qué recursos requiere incorporar de acuerdo con sus necesidades" (Montoya, 2001, 189).

En este orden de ideas, el SCN 1993 (Naciones Unidas et al., 1993) ha constituido un avance importante para la Contabilidad Nacional en lo respectivo a lo ambiental, en tanto que en este "se realiza el análisis medioambiental en el contexto de un marco amplio que modifica varios conceptos del SCN, para responder a la preocupación creciente por la aplicación de criterios sobre el tratamiento e incorporación de los recursos naturales y el ambiente al análisis económico haciendo operativos los conceptos de crecimiento y desarrollo sostenible. Las explicaciones se basan en gran medida en el Sistema de Contabilidad Ambiental y Económica Integrada (SCAEI) que se presenta en el Manual de Contabilidad Económica y Ambiental Integrada (MCEAI), elaborado por la División de Estadísticas de las Naciones Unidas" ( Torres et al., 2001, 69). No sobra resaltar, que el SCN 1993, ha tenido una quinta revisión en el año 2008, lo cual dio origen a una nueva versión, conocida como SCN 2008, la cual fue el resultado del trabajo que viene realizando desde hace más de cincuenta años las Naciones Unidas, pero esta vez con la participación conjunta de otros organismos internacionales como la Comisión Europea, la Organización para la Cooperación y el desarrollo Económico, el Fondo Monetario Internacional y el Grupo del Banco Mundial. En esta nueva versión, hay unos cambios y sugerencias para la presentación de las cuentas satélites de ambiente. En la actualidad, el DANE viene trabajando con la versión del SCN 1993 de Naciones Unidas.

Sin embargo, la introducción del componente ambiental en las Cuentas Nacionales de los países de América Latina y el Caribe ha tenido un desarrollo parcial y desigual, si bien es cierto que a comienzos de los noventas varios países latinoamericanos, auspiciados por organismos internacionales elaboraron proyectos, algunos de carácter experimental para iniciar el cálculo de las cuentas ambientales, la mayoría de ellos no fueron concluidos, ya sea por falta de capacidad técnica o por no disponer del financiamiento necesario. Sin embargo, el tema ha sido retomado en años recientes y es así como varios países de la región hoy en día han comenzado a elaborar planes para implementar en los próximos años un SCSA (Isa, Ortúzar \& Quiroga, 2005).

En la tabla 3 se puede apreciar la situación actual en América Latina en lo respectivo al tema de Cuentas Nacionales Ambientales. Colombia y México son los países latinoamericanos que más han venido avanzando en la estructuración de sus propios Sistemas de Contabilidad Nacional Ambiental. Para 
Tabla 3. Situación de las Cuentas Nacionales Ambientales en América Latina a $2005^{6}$

\begin{tabular}{|l|l|}
\hline \multicolumn{1}{|c|}{ Situación } & \multicolumn{1}{c|}{ Países } \\
\hline Están elaborando sistemáticamente Cuentas Ambientales & Colombia y México \\
\hline Se encuentran desarrollando Cuentas Ambientales & Nicaragua y Panamá \\
\hline Tienen interés de desarrollar Cuentas Ambientales & Argentina, Guatemala, Honduras y República Dominicana \\
\hline $\begin{array}{l}\text { Tuvieron proyectos de cuentas ambientales y no los con- } \\
\text { cretaron }\end{array}$ & Argentina, Bolivia y Brasil \\
\hline No tienen proyectos para elaborar Cuentas ambientales & $\begin{array}{l}\text { Barbados, Cuba, Ecuador, El Salvador, Jamaica, Perú, St. } \\
\text { Kitts \& Nevis, Trinidad y Tobago, y Venezuela }\end{array}$ \\
\hline Dejaron de elaborar Cuentas ambientales & Chile y Costa Rica \\
\hline
\end{tabular}

el caso colombiano antes de que apareciera de manera oficial la revisión 4 del SCAEI, según Montoya (2001) ya se había iniciado la construcción de una metodología para el establecimiento de un Sistema de Cuentas Nacionales Ambientales y realizado varios ejercicios de contabilidad patrimonial regional siguiendo el modelo francés de las cuentas del patrimonio natural y las experiencias en Argentina, Chile y México. Para el caso francés "el patrimonio natural representa un conjunto de bienes que han sido legados por las generaciones anteriores y que se debe conservar o transformar adecuadamente para poder ser transmitidos a las generaciones futuras. Esta definición está ligada a la idea de que el patrimonio sufre menoscabo y puede perderse" (DANE, 1993, 239).

Con la creación del Comité Interinstitucional de Cuentas Ambientales (CICA) en 1992 se inició el estudio e implementación del Sistema de Cuentas Económicas Ambientales Integradas mediante el proyecto piloto de Contabilidad Económico-Ambiental Integrado para Colombia (COLSCEA), siguiendo los parámetros metodológicos estipulados por Naciones Unidas, es decir, integrando al SCN 1993 un Sistema de Cuentas Satélites. Bajo dicho proyecto se desarrollaron metodologías para: i) las cuentas del gasto en protección ambiental, ii) las cuentas físicas de los recursos naturales, y iii) las cuentas de calidad de los recursos naturales. La incorporación de dichas cuentas según Isa, Ortúzar \& Quiroga (2005) trata de responder a los siguientes aspectos: cómo se financian y cuáles son los gastos en protección ambiental, qué sectores o actividades económicas inciden en la protección del medio ambiente, cuál es el nivel de degradación y agotamiento de los recursos naturales y cuáles son las repercusiones sobre el patrimonio natural que tienen los sectores o actividades económicas.

Al concluir el proyecto COLSCEA se mantuvo la elaboración de las Cuentas Satélites de Ambiente y a través del Decreto 262 de 2004 se estableció como función tanto del DANE como de la Dirección de Síntesis y Cuentas Nacionales, la elaboración de las Cuentas Satélites. Para el año 2004 en la reunión del Grupo de Londres llevada a cabo en Copenhague, se realizó una entrevista a Cesar Caballero, Director del DANE en aquel tiempo, sobre el estado de las Cuentas Económico Ambientales Integradas, en la cual el entrevistado manifestó que:

- En Colombia el Sistema de Cuentas Económico Ambientales Integradas se estructura bajo los parámetros del Manual de Contabilidad Nacional: Contabilidad ambiental y Económica Integrada 2003, en el cual se establece la elaboración de 3 tipos de cuentas: i) las cuentas físicas de los recursos naturales, ii) las cuentas en términos monetarios, y iii) las cuentas de sostenibilidad del medio ambiente. No obstante, debido a deficiencia en la disponibilidad de información únicamente se han abordado algunos aspectos de las dos primeras cuentas.

- En lo respectivo a la contabilidad física de los recursos naturales se han elaborado: a) cuentas

$6 \quad$ Fuente: Tomado y modificado de Isa, Ortúzar \& Quiroga (2005). 
de stocks de los recursos del subsuelo y forestal, en las cuales se han cuantificado dentro de los recursos del subsuelo las reservas de carbón, petróleo, gas natural, hierro, níquel y cobre, y en lo forestal se ha conseguido la contabilización del bosque plantado con fines comerciales y protectores. De igual forma se han establecido indicadores de cambio de uso del suelo e indicadores de calidad del agua y el aire.

- En cuanto a las cuentas ambientales en términos monetarios se han implementado cuentas del gasto en protección ambiental y cuentas de servicios de saneamiento básico para los sectores público y privado. Del mismo modo, se han elaborado desarrollos metodológicos en la medición del gasto de protección en los sectores agrícola, salud y hotelero, y se avanzan estudios para los sectores transporte, minero y construcción.

- Adicionalmente, en el país se llevó a cabo la implementación de la matriz insumo-producto ambiental.

Después de haber presentado el origen y la situación de las Cuentas Nacionales Ambientales en Latinoamérica haciendo énfasis en Colombia, se procederá a realizar un análisis y una evaluación crítica de la información suministrada por el SCN de Colombia en materia ambiental.

\subsection{SCN en Colombia: Análisis y evaluación crítica del componente ambiental}

Como se mencionó en el apartado anterior, el SCN de Colombia incorpora lo ambiental bajo la modalidad de cuentas Satélite integradas al Marco Central del SCN 1993. Como lo señala DANE (1993) en el Marco o Sistema Central de Cuentas Nacionales se articula el patrimonio natural que es expresable en términos monetarios y está vinculado a procesos de mercado (patrimonio natural económico), compuesto por los activos naturales no producidos que son económicos y hace parte del patrimonio económico total. De otro lado, el SCSA incorpora los activos naturales no producidos que son económicos y los activos naturales no producidos que no

son económicos (Patrimonio natural no económico), es decir, se incorpora en el patrimonio natural, tanto el patrimonio natural económico como el no económico.

El patrimonio natural no económico por no hacer parte de las transacciones de mercado no se incorpora directamente en el Sistema Central de Cuentas Nacionales y por ello se ha establecido Cuentas Satélites que expresen este componente del patrimonio natural en términos físicos. En la Ilustración 2 se puede observar la composición del SCN y en la Ilustración 3 la composición de las Cuentas Satélite de Ambiente en Colombia

De la Ilustración 3 se aclara que según DANE (2003) las cuentas de sostenibilidad, relacionadas con los gastos de repercusión de las actividades económicas en el ambiente, casi no se encuentran desarrolladas, motivo por el cual no se abordaran en el presente documento. Ahora bien, pese a que este $\mathrm{SCN}$ se constituye en un avance en el ámbito ambiental, presenta algunos problemas dentro de los cuales Talero (2007) señala los siguientes:

- $\quad$ El SCN pretende que se plasmen los flujos reales de los recursos naturales de no mercado, es decir de los bienes públicos o recursos comunes que no poseen un precio en el mercado por su naturaleza, junto con los bienes y servicios que si son de mercado.

- Las Cuentas Satélites de Ambiente son tratadas como apéndices informativos supeditados al Marco Central del SCN 93, lo cual le resta relevancia a su papel informativo sobre el impacto

Ilustración 2. Composición del SCN en Colombia ${ }^{7}$

\section{Sistema de Cuentas Nacionales de Colombia}

Marco o Sistema Central
de las Cuentas Nacionales Comprende el registro de las operaciones
económicas y el patrimonio económico
(Activos producidos por el hombre y activos no producidos que son económicos)
Cuentas Satélites

Las cuentas satélites permiten ampliar la descripción de un tema mediante cuadros e indicadores aplicables a temas especificos" DANE, 2003, pp. 3) actualmente se encuentran desarrollando cuatro cuentas satélites: salud y seguridad social, cultura, turismo y ambiente

7 Fuente: Elaboración propia con base en $\operatorname{DANE}(1993,2003)$. 
Ilustración 3. Composición de las Cuentas Satélite de Ambiente en Colombia ${ }^{8}$

\begin{tabular}{|c|c|c|}
\hline \multicolumn{3}{|c|}{ Cuentas Satélites de Colombia } \\
\hline \multicolumn{3}{|c|}{$\begin{array}{l}\text { "Tienen como finalidad cuantificar los fenómenos de deterioro y mejoramiento del medio } \\
\text { ambiente, el estado de los recursos naturales y los gastos destinados al medio ambiente. Se } \\
\text { caracterizan por inscribirse bajo el marco de las cuentas nacionales. Se diferencian de este en } \\
\text { cuanto a que amplían el concepto de patrimonio natural" (DANE, 2003, pp. 3). Estas cuentas } \\
\text { satélites se encuentran conformadas por tres componentes: }\end{array}$} \\
\hline $\begin{array}{l}\text { Cuentas ambientales de } \\
\text { los recursos naturales en } \\
\text { términos físicos }\end{array}$ & $\begin{array}{l}\text { Cuentas ambientales en } \\
\text { términos monetarios }\end{array}$ & $\begin{array}{l}\text { Cuentas de sostenibilidad } \\
\text { del ambiente }\end{array}$ \\
\hline $\begin{array}{c}\text { Contemplan las } \\
\text { modificaciones en los stock } \\
\text { de los activos naturales no } \\
\text { producidos tanto económicos } \\
\text { (tierra, bosque natural, } \\
\text { recurso hídrico y los activos } \\
\text { del subsuelo) como no } \\
\text { económicos (las reservas } \\
\text { hipotéticas del subuselo, } \\
\text { animales silvestres, los } \\
\text { peces, los mares y océanos } \\
\text { y el aire) }\end{array}$ & $\begin{array}{l}\text { Se encargan de la valoración } \\
\text { del patrimonio natural, y } \\
\text { de la cuantificación de los } \\
\text { costos ambientales como } \\
\text { deforestación, agotamiento, } \\
\text { erosión, etc., y de los gastos } \\
\text { en proteción ambiental } \\
\text { realizados por los diversos } \\
\text { agentes económicos, en } \\
\text { estas cuentas también se } \\
\text { contemplan las cuentas de } \\
\text { producción y generación del } \\
\text { ingreso de las actividades } \\
\text { económico ambientales de } \\
\text { acueducto, alcantarillado y } \\
\text { reciclaje }\end{array}$ & $\begin{array}{l}\text { Relacionadas con los } \\
\text { gastos de repercusión }\end{array}$ \\
\hline
\end{tabular}

de las actividades económicas en la sostenibilidad del desarrollo económico y el bienestar de la sociedad.

Por otro lado, este sistema también presenta incoherencias en sus mediciones, dentro de las cuales se encuentran: i) considera como producción y no como depreciación el agotamiento de los recursos naturales, ii) los gastos de "protección" y de "reparación" del ambiente son contabilizados como bienes finales que incrementan los ingresos y no como bienes intermedios de las actividades económicas que causan perjuicios al ambiente, con lo cual se cae en una doble contabilización, y iii) la degradación del ambiente no es considerada por el SCN y por ende omite la reducción de las capacidades futuras que posibilitaran un ingreso equivalente o superior al actual.

\subsection{Análisis de la información del Sistema de Cuentas Satélites de Ambiente emitida por el DANE}

Sin olvidar los aportes y problemas del SCSA, se pasa a hacer una revisión de la información que ha sido emitida por el DANE en materia ambiental, con el fin de identificar las potencialidades, las limitaciones $y$ las críticas que surgen y formular consideraciones que pueden dar luces para continuar avanzando en la construcción de las cuentas satélites ambientales.

Partimos de considerar que la forma de acceder libremente a la información disponible sobre cuentas satélites ambientales en Colombia, es ingresando en la página web del DANE. Allí, en el vínculo de cuentas nacionales se encuentran las cuentas satélites y a su vez dentro de estas se hallan las de ambiente. En la página web en lo correspondiente a cuentas satélites de ambiente se plantea en primera medida cómo se deben realizar las cuentas, teniendo como base la ficha metodológica de cuentas económico ambientales. Seguido de esta ficha metodológica se presentan cinco apartados, los tres primeros asociados a las cuentas económico ambientales y los siguientes un glosario de los conceptos de estas cuentas satélites de ambiente y un video que habla la razón de ser de estas cuentas y los aportes de dichas cuentas en la formulación de políticas públicas.

Los títulos de las cuentas económico ambientales son: gasto en protección ambiental 2000 - 2009, cuentas físicas de stock, índices de calidad ambientales, series históricas y otras publicaciones (gasto en protección ambiental, emisiones de fuentes móviles). En cada uno se incluyen las fichas metodológicas, los boletines emitidos y cuadros con los datos utilizados de los diferentes sectores o actividades.

Se inicia la revisión con las series históricas y otras publicaciones, donde hay información del gasto en protección ambiental, con datos de los sectores de gobierno, industria y reciclaje mostrando el gasto $y$ la producción por finalidad, se presentan cuadros de producción y formación de capital. También hay datos de gastos por finalidad para agricultura, pero estos no están incluidos en el boletín de las cuentas de stock. En dichos cuadros toman la información de cultivos de caña, arroz, palma africana y banano, cultivos considerados como industriales sobre los cuales hay reparos en términos ambientales.

Para el caso de la caña de azúcar y del cultivo de flores, Pérez $(2006,222)$ plantea que "Los patrones de consumo externo, a través del comercio interna-

8 Fuente: Elaboración propia con base en DANE (1993, 2003). 
cional, trasladan buena parte de los costos sociales y ambientales a territorios y zonas específicas dentro de un país. De tal manera, los patrones de especialización promovidos por el libre comercio tienen efectos concretos sobre regiones y grupos de poblaciones particulares que son afectadas ambiental y socialmente. Esta situación, genera además conflictos ecológicos distributivos entre la población que usa los recursos ambientales para sus actividades tradicionales en una zona particular y la demanda creciente de los mismos por parte de la actividad exportadora. Estos conflictos producen problemas de gobernabilidad para las autoridades locales por el gran poder económico y político de los agentes exportadores". En este sentido, la construcción de las cuentas ambientales pueden apostarle a retomar el enfoque de Pérez a la hora de emitir información y evaluar los impactos de los monocultivos sobre el agua y los suelos, teniendo en cuenta los efectos que esto genera para las poblaciones rurales y urbanas, para los ecosistemas y para la gobernabilidad, afectando la defensa de lo público y su construcción bajo el interés de las comunidades que habitan el territorio colombiano, en sus diversos niveles de territorialidad.

Ahora bien, confrontando la Metodología de la Cuenta Satélite de Medio Ambiente de Colombia publicada en 2003 por el DANE con la información suministrada por la misma entidad en su página web se encuentra que la matriz oferta y utilización ambiental, no se localiza con facilidad en la página del DANE, existe una única matriz en la cual no se indica a que periodo corresponde. Por ello se dificulta el análisis de la misma y el acceso adecuado a la información sobre el ambiente establecido en el Principio 10 de La Conferencia de las Naciones Unidas sobre el Medio Ambiente y el Desarrollo realizada en Río de Janeiro en 1992.

De otro lado, las Cuentas Satélites de turismo tienen disponible la ficha metodológica, y tablas de la cuenta sobre el consumo turístico receptor por productos (Gasto en Efectivo del Consumo Final del Visitante) del año 2000. Desagrega por distintas formas de servicio de alojamiento, transporte, y demás servicios culturales y recreativos que se ofrecen. Muestra un rubro de servicios turísticos diversos pero no se sabe, si por ejemplo, allí se encuentra el ecoturismo que debería estar desagregado para efectos de las Cuentas Satélite de Ambiente.

Por otra parte, como se mencionó en la sección 3.1., en la Reunión del Grupo de Londres, Caballero (2004) dio un informe sobre los avances del país en el tema de Cuentas Nacionales Ambientales. Caballero plantea que en el país se trabajan tres enfoques: las cuentas físicas de los recursos naturales, las cuentas en términos monetarios, y las cuentas de sostenibilidad del medio ambiente. También señala lo que se había hecho a la fecha, en que estaban trabajando, y los planes de acción a futuro. En comparación con la información disponible en la web del DANE, encontramos que algunos componentes de la información que según Caballero estaba disponible en el 2004, no está disponible en 2011. Se trata de las cuentas físicas del recurso forestal, del cual se planteaba un avance, los indicadores de cambio de uso del suelo. Caballero (2004) menciona los desarrollos metodológicos para sectores como el agrícola, servicios en salud, y hotelería, estudios en los sectores minero, construcción, y transporte, pero aún no hay cuentas o indicadores disponibles. Según esto se estaba elaborando cuentas para servicios de alcantarillado, recolección de basuras y reciclaje; esa información tampoco está disponible.

Por otra parte, revisando la información reportada en las diferentes Cuentas Satélites de Ambiente, se evidencia que existen falencias en la información proporcionada por el DANE. En algunos casos debido, como se mencionó en la sección 3.2., a incoherencias en las mediciones de las Cuentas Satélites de Ambiente (como en el caso de los gastos de protección ambiental) y en otros a la dispersión o no disponibilidad de información ambiental en su página web dificultando el acceso adecuado a dicha información para la formulación de política pública ambiental. Así mismo, sabemos que el alcance de la información que reporta el DANE es de carácter estadístico, sin embargo pueden contemplarse otras maneras de fortalecer esta información, porque no es suficiente evaluar la inversión en lo ambiental, es necesario conocer el impacto. Otro inconveniente se encuentra relacionado con la forma en que se construyen las metodologías para emisión de la informa- 
ción, pues no se revelan mecanismos de participación de sectores de la población.

\subsubsection{Revisión y análisis del marco metodoló- gico y la información de los boletines de prensa, relativos al Sistema de Cuentas Satélites de Ambiente}

El avance, las potencialidades y los vacíos de las Cuentas Satélites de Ambiente se evalúan a continuación revisando la información generada por el DANE, a partir de la metodología de las Cuentas Satélites de Ambiente, las fichas metodológicas y de los boletines respectivos de las Cuentas Económico Ambientales. Para ello, se aborda el análisis partiendo de los temas de las fichas metodológicas y los respectivos boletines de prensa que le corresponden, estos son:

- Cuentas monetarias, gastos en protección ambiental
- Cuentas físicas, índices de calidad ambiental.

- Cuentas económico ambientales.

- Cuentas físicas de activos naturales.

- Encuesta ambiental industrial EAI.

- Compendio de estadísticas asociadas al Desarrollo Sostenible.

En la Tabla 4 se presenta el resumen de la información emitida por el DANE para Cuentas Satélites (Fichas metodológicas y boletines de prensa). Como se muestra aunque el trabajo de elaboración de Cuentas Satélite de Ambiente se inició en 1992, solo hasta ocho años después el DANE emitió boletines con información de algunas cuentas. Hasta el momento no hay una regularidad de emisión de la información, lo que está disponible es lo que se presenta en el cuadro.

Las cuentas económico ambientales, es la ficha metodológica de referencia, de la cual se desprende

Tabla 4. Resumen de la información emitida por el DANE para Cuentas Satélite de Ambiente ${ }^{9}$

\begin{tabular}{|c|c|c|}
\hline \multirow{2}{*}{ Ficha metodológica } & \multicolumn{2}{|c|}{ Boletines emitidos } \\
\hline & Fecha de emisión & Información emitida (años y sectores) \\
\hline \multirow[t]{2}{*}{$\begin{array}{l}\text { Cuentas monetarias, gastos en protección ambiental. } \\
\text { Octubre de } 2007 \text { (DANE, 2007a) }\end{array}$} & 3 de diciembre de 2010 & $\begin{array}{l}2000 \text { a } 2007 \text { gobierno y reciclaje, } 2000 \text { a } 2006 \text { industria } \\
\text { manufacturera (DANE, 2010b). }\end{array}$ \\
\hline & 30 de diciembre de 2010 & $\begin{array}{l}2007 \text { y } 2008 \text { gobierno, industria manufacturera y reciclaje } \\
\text { (DANE, 2010c). }\end{array}$ \\
\hline $\begin{array}{l}\text { Cuentas físicas, índices de calidad ambiental. Marzo } \\
\text { de } 2007 \text { (DANE, 2007b). }\end{array}$ & 3 de diciembre de 2010 & 2000 a 2007 industria manufacturera (DANE, 2010e). \\
\hline $\begin{array}{l}\text { Cuentas económico ambientales. No presenta fecha } \\
\text { (DANE, s.f) }\end{array}$ & No hay boletines emitidos & \\
\hline $\begin{array}{l}\text { Cuentas físicas de activos naturales. Marzo de } 2007 \\
\text { (DANE, 2007c) }\end{array}$ & Julio de 2010 & $\begin{array}{l}\text { Recursos naturales de 2008. Series históricas de petró- } \\
\text { leo, carbón y gas natural de } 1994 \text { a 2008, de hierro, cobre } \\
\text { y níquel del } 2000 \text { al 2008. (DANE, 2010d) }\end{array}$ \\
\hline $\begin{array}{l}\text { Encuesta ambiental industrial EAl. Junio de } 2010 \\
\text { (DANE, 2010a). }\end{array}$ & diciembre de 2010 & $\begin{array}{l}\text { Información del 2008, por corredores industriales y acti- } \\
\text { vidades económicas (DANE, 2010a) }\end{array}$ \\
\hline $\begin{array}{l}\text { Compendio de estadísticas asociadas al Desarrollo } \\
\text { Sostenible. Julio de } 2008\end{array}$ & No hay boletines emitidos. & \\
\hline
\end{tabular}

9 Fuente: elaboración propia basado en la información de la página web del DANE (2011). 
como objetivos preparar información de gasto en protección ambiental, información en términos físicos, cuentas físicas del patrimonio natural para recursos no renovables e indicadores de calidad ambiental (DANE, s.f).

Las variables a representar en las cuentas se dividen en escenario económico, escenario físico biótico, calidad de los recursos e indicadores. Veremos que en la práctica, hay información sobre las variables, pero se presentan de manera separada, sin un análisis que permita conocer los impactos tanto de las actividades que generan problemas ambientales, como de las acciones que buscan sanearlos.

Es importante señalar que las variables definidas en la ficha metodológica, el aspecto físico-biótico se trata como mercancías, aunque recurre a mostrar información en términos físicos, trata las variables como inventarios en la contabilidad tradicional financiera.

Las cuentas físicas de activos naturales, tienen como objetivo "Establecer un balance de los recursos objeto de estudio, en términos físicos para un año contable" (DANE, 2007c, 1), por tanto la información a emitir se limita a inventariar, no busca establecer impactos sobre estos activos naturales. Las variables que miden son acervo de apertura (-), agotamiento, descubrimientos (-), otros cambios de volumen y acervo de cierre. Por ello las reservas calculadas obedecen tanto a variaciones en las cantidades como a cambios en las formas de medir las reservas.

Ahora, la población objetivo considera petróleo, gas natural, carbón, níquel, cobre y hierro. En el caso del petróleo las reservas disminuyen, por tanto disminuye la riqueza. Como se evidencia la mira de esta cuenta esta en los recursos minero-energéticos. Actualmente este sector es considerado como una locomotora de desarrollo del país, pero presenta muchos cuestionamientos frente a las afectaciones ecológicas y socioculturales.

Si la información de Cuentas Satélite de Ambiente se centra en este tipo de recursos, ¿qué pasa con los bosques, las cuencas hídricas (seriamente afectadas por la minería), y con la biodiversidad? ¿Cuál es el orden de prioridades de lo ambiental? Pareciera que el objetivo de esta cuenta es tener información de la disponibilidad de estos recursos no renovables, que si bien son importantes para el crecimiento económico, su explotación genera serias problemáticas ambientales. En este sentido pierde sentido la información de esta cuenta, si no existe un mecanismo para establecer el impacto de su extracción, como condición para determinar políticas tendientes por lo menos a disminuir los impactos.

Como se mencionó en párrafos anteriores, a partir de las fichas metodológicas se elabora la información de las Cuentas Satélites de Ambiente, ésta información es publicada por medio de Boletines de Prensa del DANE. Por ello, a continuación se presentan algunas consideraciones que buscan aportar a la manera como se presenta la información y el contenido de la misma, teniendo presente el propósito de que esta información se constituya en un aporte a la formulación de política pública.

Las cuentas monetarias, gastos en protección ambiental, se consideran como variables. Al iagual que la producción, valor agregado, remuneración a los asalariados, impuestos sobre producción, formación bruta de capital fijo y venta de otros bienes y servicios (DANE, 2007a). Claramente retoma criterios de presentación de la información, del Sistema de Cuentas Nacionales. Al respecto vale la pena preguntarse ¿esa manera de presentar la información, es útil para evaluar si ese gasto verdaderamente aporta a la protección ambiental?

El gasto en protección ambiental muestra dos cuentas, la de producción y generación del ingreso, y la cuenta de capital con propósitos ambientales. La destinación de recursos en la cuenta de capital es principalmente en construcciones y edificaciones no residenciales. Sin detenernos en revisar el monto de recursos destinados para este rubro, ¿Cuál es el aporte de esta cuenta a la protección ambiental?

Su población objeto se descompone en dos. i) Actividades de producción ambiental (alcantarillado, recolección de residuos, administración del medio 
ambiente del gobierno y reciclaje; y ii) actividades auxiliares (gobierno, industria, agrícola, construcción, transporte, explotación de petróleo, gas natural y carbón).

La información emitida es para reciclaje, para gobierno e industria manufacturera, de las demás actividades no hay información. De cada sector se muestran las cifras y las variaciones, pero no hay un análisis del impacto de este gasto de protección ambiental. De la información disponible para la industria, no muestra cuál es el porcentaje de este gasto en relación con los gastos totales de la industria, lo cual es importante para comparar y mirar el impacto sobre los gastos, esta cifra por sí misma no dice mucho.

Las cifras se complementan con análisis, pero los de estos boletines solo detallan las variaciones en las cifras y poco aportan a lo ambiental. Es importante reforzarlo, porque el objetivo se reduce a "medir el esfuerzo para proteger y conservar los recursos naturales" (DANE, 2010b, 2), pero no se evidencia como aporta a la protección y conservación de los recursos naturales.

Como muestra la tabla 4 solo se ha generado información para reciclaje, el gobierno y la industria. Parece que no se tiene en cuenta siquiera la clasificación de actividades de protección ambiental (CAPA), que tiene en cuenta la protección del aire, ambiente y clima, gestión de las aguas servidas, gestión de desechos, protección del suelo y las agua freáticas, atenuación del ruido y las vibraciones, protección de la diversidad biológica y el paisaje, protección contra la radiación investigación y desarrollo.

El énfasis es en recursos minero energéticos, sobre los cuáles más que una preocupación por su agotamiento (de interés para garantizar la oferta energética y por ende para el crecimiento económico), hay una fuerte inquietud por los impactos de la explotación de estos recursos, principalmente por afecciones sobre el agua, los suelos y la salud humana.

Cuando las cuentas de los recursos naturales se centran en pocos recursos, como lo muestran las cuentas de stock que considera solamente los recursos minero energéticos, parece que esa fuera la prioridad de conservación para Colombia, cuando durante los gobiernos de Uribe se incrementó la extracción, y actualmente lo que hay es un interés por volver este sector una locomotora de la economía y, por tanto, extraer y disminuir los recursos.

El gasto en protección ambiental busca medir el grado de compromiso de los sectores involucrados, como indicador podría compararse tomando como referencia el tamaño de la economía, es decir comparado con el Producto Interno Bruto-PIB. Según el Boletín de Prensa sobre gasto en protección ambiental, en el periodo 2000 a 2007 fue en promedio de $0,4 \%$ del PIB (DANE, 2010b), pero hay que compararlo con una meta de gasto con relación al PIB y eso no se muestra en el análisis. Otro tema presentado en este Boletín de Prensa es el gasto total, compuesto por la inversión y el gasto corriente. Los resultados muestran que el rubro de mayor gasto es el de administración y gestión ambiental, salvo en el 2002 que fue en investigación y desarrollo ambiental, el segundo componente de mayor gasto fue investigación y desarrollo ambiental entre el 2001 y 2004, y en 2000, 2005 a 2007 fue bosques y ecosistemas. Ello da cuenta de los esfuerzos, es verdad, pero hay que complementarlo con el análisis por parte del gasto total.

En el boletín de gasto en protección ambiental se señala que "la mayor inversión en gasto en protección ambiental del sector gobierno se realiza en construcciones y edificaciones no residenciales, es decir construcción de grandes obras de infraestructura. Para la serie cerca del $96 \%$ de la inversión se realiza en este tipo de bienes" (DANE, 2010b, 4), por tanto se inserta en el SCSA una política ambiental gris, es decir que está basada en la construcción de infraestructura más no en soluciones reales y efectivas de la problemática.

Ahora respecto al gasto en protección ambiental del sector gobierno, desde el 2000 este se mantuvo en aumento, pero en el 2007 disminuyó. Lo cual teniendo en cuenta que "Las cuentas de gasto en protección ambiental son de utilidad para el análisis de políticas ambientales y en cierta medida reflejan el grado de compromiso de los sectores de la economía con el uso sostenible de los recursos naturales y el buen estado del medio ambiente. Además, brindan información acerca de la disponibilidad de bienes $y$ 
servicios del sector ambiental, por cuanto registran información sobre inversión y gasto por finalidad ambiental, según la actividad económica correspondiente. Al relacionar la información del gasto en protección ambiental con los registros físicos del estado de los activos naturales (cuentas físicas de stock), es posible reconocer las acciones realizadas o necesarias para la protección de los recursos más afectados." (DANE, 2010b, 2). Esto corrobora lo expresado en el análisis de la política ambiental de los periodos de gobierno, mostrando para el último periodo de Uribe menores esfuerzos, para este caso en la protección ambiental, a partir de los gastos del sector gobierno.

La actividad de reciclaje muestra un incremento en la producción de reciclaje que se cuenta dentro de la cuenta de gasto en protección ambiental (toma en cuenta vidrio, papel, cartón, metales y plástico) entre el 2000 y el 2007. Se está avanzando en este campo pero lo ambiental no se puede dirigir solo al reciclaje, sin embargo, es importante para la gestión urbana, que debe ir en un complemento entre información y gestión para promover el reciclaje.

Las cuentas físicas de activos naturales, estas cuentas buscan cuantificar la naturaleza en términos físicos, para dar cuenta de su estado. La ficha metodológica de estas cuentas "establece un balance de los recursos objeto de estudio, en términos físicos, para un año contable" (DANE, 2007c, 1), solamente para aquellos que implican un uso económico. En la medida que se tiene en cuenta como recursos solo aquellos que dan un aporte a la economía, el paradigma que predomina es el de sostener los recursos para sostener la economía, sin un compromiso con lo ambiental.

Las cuentas físicas de los recursos naturales contemplan las modificaciones en los stock de los activos naturales no producidos tanto económicos (tierra, bosque natural, recurso hídrico y los activos del subsuelo) como no económicos (las reservas hipotéticas del subsuelo, animales silvestres, los peces, los mares y océanos y el aire). No obstante, la población de objeto de estas cuentas son los recursos minero energéticos (petróleo, gas natural, carbón, níquel, cobre y hierro), así el énfasis continua sobre los recursos del subsuelo, descuidando aquellos recursos que tie- nen que ver con actividades como la agricultura, el ecoturismo que han sido política de varios gobiernos; es decir, dejan de lado los bosques y la tierra, los suelos, entre otros. Eso representa un vacío en la información, pues Colombia posee una gran variedad de riqueza mineral que no se limita a estos seis recursos, de hecho el país también se destaca por la producción de plata, platino, oro, esmeraldas, plomo, titanio, zinc, manganeso, sal, azufre, yeso, mármol, caliza, entre otros, para los cuales no se han desarrollado cuentas físicas.

De otro lado, existe una cuenta física de los bosques plantados con fines comerciales en la cual se debe discriminar el stock inicial (área total existente de bosque), el área aprovechada, el área plantada o establecida y el Stock final. No obstante, dicha información relativa a los bosques no es publicada en la página web del DANE, lo cual dificulta el acceso adecuado a la información sobre el medio ambiente establecido en el Principio 10 de la Conferencia de Rio de Janeiro (CNUMAD, 1992).

En lo que vimos del origen y construcción de las cuentas ambientales en Colombia, la base es el SCAEI 2003 (Naciones Unidas et al., 2003), para las cuentas de recursos naturales por ejemplo este manual propone la contabilidad de tierras y terrenos como parte de las cuentas de activos forestales, y con información de la erosión del suelo. Sobre este tema en Colombia se plantea como inconveniente problemas con la medición y falta de claridad y definición de los derechos de propiedad, y claro es una razón muy válida, pero por lo menos se debería empezar a entregar información sobre los terrenos que tienen derechos de propiedad asignados.

Sobre índices de calidad para los recursos de agua $y$ aire, no se pueden determinar stocks de apertura y de cierre porque no se pueden medir en términos cuantitativos, pero se estudia una calidad inicial y una final. La cuenta física de calidad para estos recursos consta de las siguientes mediciones: calidad ambiental inicial, volumen de vertimientos o emisiones, y calidad ambiental final (DANE, 2007b).

En la sección de índices de calidad ambientales solo hay información de los vertimientos y emisiones in- 
dustriales, pero en ningún lugar se presenta información sobre la calidad inicial y la calidad final del agua y del aire. En este sentido no se estaría cumpliendo con el objetivo de determinar la calidad de los activos naturales no contabilizables (recursos hídrico y atmosférico), para un periodo de tiempo como lo establece el DANE (2003). La información reportada se restringe a determinar el volumen de vertimientos $y$ emisiones que afectan negativamente el estado natural de agua y del aire.

La Encuesta ambiental industrial EAI, esta encuesta tiene como objetivo "obtener información de la inversión, costos y gastos asociados a la protección del medio ambiente, la generación de residuos sólidos, el manejo del recurso hídrico y los instrumentos de gestión de la industria manufacturera" (DANE, 2010a, 22). La ficha metodológica considera trece parámetros a medir, por su parte el boletín presenta información de seis: instrumentos de gestión ambiental, existencia de certificaciones ambientales y estado, existencia de instrumentos de planeación ambiental, deducciones por incentivos tributarios de carácter ambiental, inversión y gasto en protección ambiental, otros costos y gastos asociados a la protección ambiental.

El boletín plantea que "los resultados totales de inversión, costo y gasto, gestión ambiental, generación, manejo y disposición de residuos sólidos y manejo del recurso hídrico se encuentra en proceso de análisis, razón por la cual no se presenta esta información" (DANE, 2010a, 2). Para este caso, es explicita la ausencia de información que no ha sido incluida en este boletín por que no ha sido posible obtenerla, pero no se conoce de que trata el análisis que le están haciendo a esta información que falta.

Por su parte la población objetivo se clasifica de dos maneras, primero por corredores industriales (Antioquia, Caribe, altiplano Cundiboyacense, Eje cafetero, Pacifico y Santander); y segundo, por actividades económicas del Código Industrial Internacional Uniforme (CIIU), de las cuáles también hay información para todas las actividades.

Si miramos la información reportada por el boletín de cuentas físicas, índices de calidad ambiental de diciembre de 2010 (DANE, 2010b), vemos datos de la inversión, gastos y costos en protección ambiental, en acciones como protección del aire y clima, gestión de aguas residuales, gestión de residuos, protección del suelo, aguas subterráneas y superficiales, reducción del ruido y protección de la biodiversidad y los paisajes. Esta encuesta en comparación con la cuenta de gasto para protección ambiental incluye temas relevantes para la gestión ambiental. Este tipo de información resulta más útil para evaluar temas de política contemplados en los PND como son los suelos, el agua y la biodiversidad.

Los conceptos de los costos y gastos son: i) pago de licencias, permisos, tasas y multas ambientales; ii) actividades de capacitación y educación ambiental; iii) gastos relacionados con procesos de gestión, investigación y desarrollo (básica, experimental o aplicada); iv) contribuciones ambientales; v) gastos de personal dedicado a actividades de protección ambiental; y, vi) otros costos y gastos no relacionados. El destino de los costos y gastos ambientales difiere en gran medida de los conceptos de la cuenta de gastos para protección ambiental, dirigidos principalmente a infraestructura.

Esta encuesta también mira los instrumentos económicos y de planeación de la industria manufacturera, los que se usaron en 2008 fueron la certificación ISO 14001 y el sello ambiental colombiano, y beneficios tributarios. De tal forma, dicha encuesta no se limita a cuantificar gastos, sino que amplía su mirada hacia instrumentos de gestión. Queda por evaluar la calidad de estos instrumentos de gestión y la efectividad no en términos de cumplimiento de las normas establecidas, sino de un aporte efectivo en lo ambiental.

\section{Una reflexión de la información de las Cuentas Satélites de Ambiente publicada por el DANE en relación con la política pública}

La política ambiental debe apuntar a solucionar problemáticas de corte ambiental, y por tanto que involucren aspectos ecológicos, económicos y sociales. Esas problemáticas están definidas por el contexto del país, las prioridades ambientales deberían responder a ese contexto, este análisis se abor- 
da de manera rápida, generando preguntas que dejan en remojo una evaluación de la pertinencia de la información del SCSA para la formulación de políticas públicas coherentes con las prioridades del país.

Como afirma Montoya (2001) cada país debe establecer sus prioridades y necesidades en materia ambiental, como paso inicial a la construcción del SCSA. Estas prioridades se insertan como primer referente en los PND, recordemos entonces las prioridades establecidas en estos documentos de política pública y su respectivo análisis.

El PND (1994-1998) proponía como estrategia de protección ambiental las reservas naturales, y enfatizó en la educación ambiental y la biodiversidad. En términos de la protección ambiental, el SCSA lo toma en cuenta como gasto de protección ambiental. La información disponible muestra el gasto del gobierno en dos cuentas, la de producción y la de capital, las cuáles reflejan la distribución de los recursos en conceptos contables (formación bruta de capital fijo, consumo intermedio, valor agregado) que no aportan a conocer, por ejemplo, si el gasto se destinó a las reservas naturales, o a programas de educación ambiental.

Según Tobasura (2006) el PND (1994-1998) plantea como acciones la planificación del manejo y aprovechamiento de recursos naturales, la conservación, la restauración o sustitución y la protección de la diversidad e integridad del ambiente. La pregunta que nos surge es, ¿cómo puede reflejarse esto en el SCSA en Colombia?

La planificación y el ordenamiento territorial se plantean como elementos importantes, y en términos de una mirada global la información sobre las tierras, sus clasificaciones según las condiciones que tienen y el tipo de propiedad pueden ser importantes para aportar a la formulación de políticas públicas. Esto debe ser complementario con lo propuesto en el PND (1994-1998) de los Estudios de Impacto Ambiental (EIA), que abordan casos particulares y sectores, y tienen el potencial de constituirse en una fuente de información para la construcción de las cuentas a niveles local y regional.
En el siguiente PND (1998-2002) el agua se perfilaba como eje articulador de la política. Plantea una estrategia de protección ambiental, con un énfasis regional, que consistía en retomar el concepto de ecosistemas estratégicos para definir ecorregiones.

Como aporte a la gestión ambiental el PND (19982002) planteaba promover la apropiación social de la información. Al respecto se han realizado esfuerzos, de manera que la información que se emite en materia ambiental está actualmente agrupada en el Sistema de Información Ambiental de Colombia (SIAC), entendido como "el conjunto integrado de actores, políticas, procesos, y tecnologías involucrados en la gestión de información ambiental del país, para facilitar la generación de conocimiento, la toma de decisiones, la educación y la participación social para el desarrollo sostenible" (MAVDT, 2011). Reconociendo la poca información que se ha generado en el SCSA, ¿̇cuál es el aporte de esa información? En este punto, es importante continuar aunando esfuerzos a una tarea que busque aportar a la toma de decisiones, cuando se necesita un sistema de información ambiental que tenga gran alcance, esta es una reflexión que es necesaria realizar a la luz de los desarrollos del SIAC.

En esos dos periodos de gobierno, entre 1994 y 2002 se encuentra como punto común de la política la protección ambiental, con diferentes estrategias que se relacionan con el ordenamiento territorial, el primero apuntó a las reservas naturales, y el segundo buscaba trabajar en el manejo de las ecoregiones.

Tomemos como referente el PND (1994-1998), en el cual " $\mathrm{El}$ ordenamiento ambiental del territorio se constituirá como instrumento fundamental para la planificación y gestión nacional, regional y local" (Tobasura, 2006, 13). Para este tema ¿̇cómo aporta y puede aportar a este propósito el SCSA?

Según Montoya (2001) una de las tareas emprendidas por el COLSCEA fue trabajar en las cuentas patrimoniales de las regiones y recursos, hasta ese año quedo como una tarea pendiente. La generación de información por regiones continua siendo un reto que es importante trabajar, puesto que Colombia cuenta con diversidad de ecosistemas y de recursos, que de- 
ben ser manejados a la luz de los problemas entre crecimiento económico y afectaciones sociales y ambientales. Se podría avanzar en mirar cómo se distribuye la tierra, el tipo de propiedad, actividades económicas vinculadas y estado de los recursos naturales para conformar indicadores de sustentabilidad.

En el PND (2002-2006) la sostenibilidad ambiental adquiere una orientación basada en la economía de mercado, que buscaba la promoción de bienes y servicios ambientales, mercados de agua e incremento del empleo verde, de impulso de la biotecnología y esfuerzos para dar cabalidad al Convenio de Diversidad Biológica. El PND (2006-2010), por influencia de la CNP involucró como temas ambientales la protección del ambiente marino, políticas para regiones amazónica y pacífica, sobre biodiversidad, disminución de la degradación ambiental. Además es el único PND que pone explícitamente como tarea el desarrollo de cuentas nacionales ambientales como instrumento de planificación, e insumo para la toma de decisiones.

En general los dos gobiernos de Uribe han tenido "un modelo extractivista de exploración, explotación y exportación de las riquezas de la naturaleza en bruto (carbón, ferroníquel, petróleo, gas, etc.) eso es, sin ningún proceso de agregación de valor. Y ciertamente en los últimos años la balanza de pagos se ha sustentado sobre estos bienes primarios de exportación" (Moreno, 2010, 298). De hecho en el análisis del Sistema de Cuentas Satélites Ambientales de Colombia, se denota como la información generada se da para los recursos minero energéticos, mientras el país presenta otras prioridades.

En la política de los PND se han establecido como prioridades la protección ambiental, con estrategias que tocan el ordenamiento territorial, temas de agua, forestal, y de recurrencia en todos los PND, de biodiversidad. Veamos ahora si los PND y la información emitida del SCSA aporta a las prioridades de Colombia a la luz de sus problemáticas. Fonseca, Rincón \& Valderrama $(1997,17)$ plantean "no se pueden omitir las diferentes relaciones entre pobreza, narcotráfico, comercio, apertura, violencia y medioambiente; desde este punto de vista el análisis debe incorporar los aspectos relativos a la política agrícola, social, urbana, de competitividad, de ciencia y tecnología". La información reportada por el DANE del SCSA no refleja estos aspectos que se constituyen en prioridades reales y consecuentes con el contexto colombiano.

Se requiere de un diagnostico de las problemáticas de las comunidades, rurales, urbanas, campesinas, indígenas, afrocolombianas, y demás; como punto de partida para pasar de construir lo público solamente a través de la politike, para abarcar los asuntos de la politeia; con miras a la elaboración de políticas que respondan a las problemáticas de la realidad que viven los habitantes del país, y en consecuencia del interés común.

En este sentido la elaboración de información del SCSA debe plantearse como referente, el entendimiento del contexto socioeconómico que define las condiciones de apropiación y manejo de la naturaleza por parte de las comunidades, los sectores económicos, los hogares. Ahora hay que pensar en cómo incluir ese contexto en el desarrollo de sistemas de información ambiental.

No con el ánimo de capitalizar la naturaleza, pero siguiendo la coherencia que debería tener las Cuentas Nacionales, nos preguntamos ¿Qué pasa con la biodiversidad?, esta no se muestra aún en el SCSA a pesar de que el país es reconocido por su potencial en biodiversidad. Además la biodiversidad ha sido planteada como tema de política de los PND.

Como se vio en la revisión, de la información emitida por el DANE, es poco lo que aporta a los temas prioritarios en Colombia, se centra más en brindar información que resulta de interés para actividades extractivas como la minería. Además la información emitida presenta análisis pobres en relación con las problemáticas ambientales, lo cual hace que se extraiga del contexto colombiano. Sin una mirada sobre las problemáticas reales, el interés común está orientado a una política pública para el mercado, no para lo que interesa a los asuntos de la comunidad, descuidando el componente de politeia, que constituye una parte de la razón de ser de lo público.

\section{Conclusiones}

A partir de esta investigación y teniendo en cuenta lo señalado por Montoya (2001), cada país debe defi- 
nir cuáles son sus prioridades y aportar en la estructuración de sus Sistemas de Contabilidad Ambiental Nacional. En Colombia se requiere replantear la información que es generada por el SCSA, pues la información que es emitida por el DANE aporta poco a los temas ambientales prioritarios para el país, pues se centra más en brindar información que resulta de interés para actividades extractivas como la minería, las cuales presentan variados cuestionamientos por sus afectaciones ecológicas, económicas, sociales y culturales.

Se evidencia en la información reportada por el DANE, un marcado énfasis en el suministro de información para los recursos minero-energéticos lo cual indicaría que la conservación de estos recursos es una prioridad para el país. Mientras los PND plantean políticas para la protección ambiental, la extracción de recursos minero-energéticos ha aumentado en los últimos años.

En este sentido, las políticas esbozadas en los PND en materia ambiental se ven relegadas por las políticas de crecimiento económico, y más aún en el actual gobierno se proclaman los recursos minero energéticos como una locomotora de desarrollo para el país justificando su extracción, disminución y agotamiento. Esto debido en gran medida a que la política pública ambiental de Colombia se encuentra enmarcada bajo un modelo desarrollista-productivista con énfasis en los mercados nacionales. La información suministrada por el SCSA no contempla el contexto, ni el interés común. Está orientada a una política pública ambiental para el mercado, no para lo que interesa a la comunidad.

Por otro lado, se observa que el SCSA no es articulado con la planeación de políticas públicas ambientales en el país, como señala Talero (2007). Las cuentas satélites de ambiente son tratadas como apéndices informativos que no transforman la conciencia colectiva sobre el equilibrio que debe existir entre el beneficio del desarrollo económico y la reducción de la capacidad de autorregulación de los ecosistemas. No obstante, es indispensable que la información del SCSA sea aprovechada para efectos de la formulación de políticas públicas ambientales, pues dicha información debe orientarse a alimentar procesos que requieren controles sobre aquello que se está representando. Igualmente la formulación de políticas públicas requiere un proceso de planeación y de información adecuada para tener un soporte empírico confiable.

Para terminar, se plantea como horizonte, la investigación entorno a la comparación de experiencias significativas desarrolladas en otros países latinoamericanos (como México, entre otros) en lo correspondiente a elaboración de Cuentas Nacionales Ambientales, con el fin de diagnosticar las limitaciones y los avances del Sistema de Cuentas Nacionales Ambientales en Colombia frente a los sistemas de otros países.

\section{Referencias}

Bautista, J (2003) "Sobre lo público y los ingresos públicos". En: Giraldo, C. (Comp.) Rescate de lo Público. Poder financiero y derechos sociales. Ediciones desde abajo, 101- 123.

Caballero, C. (2004) "Reunión Grupo de Londres Cuentas Económico Ambientales Integradas". Entrevista. Copenhagen, 20-21 de septiembre. Consultado el 20 de Mayo de 2011 en http://unstats.un.org/unsd/envaccounting/ceea/meetings/ Colombia DANE.pdf

Conferencia de las Naciones Unidas sobre el medio ambiente y el desarrollo- CNUMAD (1992) Declaración de Río Sobre el Medio Ambiente y el Desarrollo (27 Principios) Rio de Janeiro, Brasil del 3 al 14 de Junio.

Daly, H. \& Cobb J. (1993) Para el bien común. Reorientando la economía hacia la comunidad, el ambiente y un futuro sostenible. Fondo de Cultura Económica. México.

Departamento de Asuntos Económicos y Sociales. División de Desarrollo Sostenible- DAES. (1992) Programa 21. Consultado el 11 de Junio de 2011 en: www.un.org/esa/dsd/agenda21_spanish

Departamento Administrativo Nacional de Estadística- DAN̄E (1993) "Patrimonio Natural de Cuentas Ambientales en Colombia: una propuesta metodológica". En: Boletín De Estadística. No 486. Colombia

Departamento Administrativo Nacional de Estadística- DANE (s.f) Ficha metodológica. Cuentas Económico-ambientales.

Departamento Administrativo Nacional de Estadística- DANE (2003) Metodología de la Cuenta Satélite de Medio Ambiente. Dirección de Síntesis y Cuentas Nacionales, Grupo de Cuentas Ambientales, Bogotá.

Departamento Administrativo Nacional de Estadística- DANE (2007a) Ficha metodológica. Cuentas monetarias. Gasto en Protección Ambiental. Dirección de Síntesis y Cuentas Nacionales - Cuenta Satélite de Medio Ambiente. Octubre de 2007.

Departamento Administrativo Nacional de Estadística- DANE (2007b) Ficha metodológica. Cuentas físicas. Índices de Calidad Ambiental. Dirección de Síntesis y Cuentas Nacionales - Cuenta Satélite de Medio Ambiente. Marzo de 2007.

Departamento Administrativo Nacional de Estadística- DANE (2007c) Ficha metodológica. Cuentas físicas de Activos Na- 
turales. Dirección de Síntesis y Cuentas Nacionales - Cuenta Satélite de Medio Ambiente. Marzo de 2007.

Departamento Administrativo Nacional de Estadística- DANE (2010a) Ficha metodológica "Encuesta Ambiental Industrial - EIA. Dirección de Síntesis y Cuentas Nacionales - Cuenta Satélite de Medio Ambiente. Diciembre de 2010.

Departamento Administrativo Nacional de Estadística- DANE (2010b) "Cuenta satélite de Medio Ambiente. Parte II - Cuentas de gasto en protección ambiental 2007" En: Boletín de Prensa. Dirección de Síntesis y Cuentas Nacionales - Cuenta Satélite de Medio Ambiente. Diciembre de 2010.

Departamento Administrativo Nacional de Estadística- DANE (2010c) "Cuenta satélite de Medio Ambiente. Cuentas de gasto en protección ambiental 2008" En: Boletín de Prensa. Dirección de Síntesis y Cuentas Nacionales - Cuenta Satélite de Medio Ambiente. Diciembre de 2010.

Departamento Administrativo Nacional de Estadística- DANE (2010d) "Cuenta satélite de Medio Ambiente. Parte I - Cuentas de stock de los recursos naturales 2008" En: Boletín de Prensa. Dirección de Síntesis y Cuentas Nacionales - Cuenta Satélite de Medio Ambiente. Diciembre de 2010.

Departamento Administrativo Nacional de Estadística- DANE (2010e) "Encuesta Ambiental Industrial 2008" En: Boletín de Prensa. Dirección de Síntesis y Cuentas Nacionales - Cuenta Satélite de Medio Ambiente. Diciembre de 2010.

Departamento Administrativo Nacional de Estadística- DANE (2011) Cuentas de gasto en protección ambiental 2009. En: Boletín de prensa.

EI Serafi, S. (1994) Sostenibilidad, medida de ingreso y crecimiento. En: Desarrollo Económico Sostenible. Avances sobre el Informe Bruntland. Bogotá. Uniandes, Tercer Mundo.

Fonseca, C.; Rincón, N. \& Valderrama, S. (1997) Productividad, Equidad y Ciudadanía. Política Ambiental. Programa de Desarrollo Económico y Social. Gente Nueva Editorial. Primera Edición.

Georgescu-Roegen, N. (1996) La ley de la entropía y el proceso económico. Madrid: Editorial Fundación Argentaria Visor Distribuciones.

Giraldo, C. (2003) "El rescate de lo público". En: Giraldo, C. (Comp.) Rescate de lo Público. Poder financiero y derechos sociales. Ediciones desde abajo.

Gómez, J. \& Rojas, J. (2011) "Contribuciones y posibilidades de los indicadores ambientales y de sostenibilidad del Sistema de Cuentas Nacionales para la formulación de políticas públicas ambientales en Colombia". Ponencia en V Congreso de Gestión Ambiental y VIII Convención Internacional sobre Medio Ambiente y Desarrollo. La Habana, Cuba.

Isa, F., Ortúzar, M. \& Quiroga, R. (2005) Cuentas ambientales: conceptos, metodologías y avances en los países de América Latina y el Caribe. CEPAL. Santiago de Chile.

Leff, E. (1998) "Globalización, ambiente y sustentabilidad del desarrollo". En: Saber ambiental. Sustentabilidad, racionalidad, complejidad y poder. México: Siglo XXI editores.

Ministerio de Ambiente y Desarrollo Sostenible- MADS (2012) Creación del Ministerio de ambiente. Consultado el 11 de Abril de 2012 en http://www.minambiente.gov.co/contenido/ contenido_imprimir.aspx?catID $=1144 \&$ conID $=6612 \&$ pag $\mathrm{ID}=6910$

Ministerio de Ambiente, Vivienda y Desarrollo Territorial- MAVDT (2011) Sistema de Información Ambiental de Colombia. ¿Qué es el SIAC? Disponible en: http://www.siac.gov.co/contenido/ contenido.aspx?catID $=69 \&$ conID $=261$.

Molina, J. (2003) "La pregunta por lo público". En: Giraldo, C. (Comp.) Rescate de lo Público. Poder financiero y derechos sociales. Ediciones desde abajo.

Montoya, C. (2001) "Contabilidad nacional, contabilidad ambiental y economía ecológica". En la roca y las mareas. Ensayos sobre economía y ecología. Editorial Unilibros.

Moreno, J. (2010) "La política ambiental en Colombia: Retroceso del paradigma de la sustentabilidad ambiental". En: Quince años de la política ambiental en Colombia. Universidad Nacional de Colombia (Sede Bogotá) Facultad de Derecho, Ciencias Políticas y Sociales. Instituto Unidad de Investigaciones Jurídico-Sociales Gerardo Molina - UNIJUS.

Murcia, D. (2009) El sistema de cuentas económico ambientales integradas. La medición de la sostenibilidad ambiental del desarrollo. Artículo presentado al IV Congreso Iberoamericano Sobre Desarrollo y Ambiente, CISDA IV, "Construyendo Modelos Alternativos de Desarrollo, Bogotá.

Naciones Unidas. (2002) Contabilidad Ambiental y Económica Integrada. Manual de operaciones. New York.

Naciones Unidas, Comisión Europea, Organización para la Cooperación y el Desarrollo, Fondo Monetario Internacional \& Banco Mundial (1993) "Sistema de Cuentas Nacionales 1993". Bruselas / Luxemburgo, Nueva York, París, Washington D.C.

Naciones Unidas, Comisión Europea, Organización para la Cooperación y el Desarrollo, Fondo Monetario Internacional \& Banco Mundial (2003) Handbook of National Accounting. Integrated Environmental and Economic Accounting- SEEA-(SCAEI, por sus siglas en español) United Nations.

Naciones Unidas, Comisión Europea, Organización para la Cooperación y el Desarrollo, Fondo Monetario Internacional \& Banco Mundial (2009) "System of National Account 2008". New York, (p. 662).

Pérez, M. (2006) Comercio internacional y medio ambiente en Colombia. Tesis doctoral, Institut de Ciencia I Tecnologia Ambientals (ICTA) Universitat Autonoma de Barcelona.

Pierri, N. (2005) "Historia del concepto de desarrollo sustentable". En: ¿Sustentabilidad? Desacuerdos sobre el desarrollo sustentable. Colección América Latina y el Nuevo Orden Mundial. México. (pp. 27-81).

Presidencia de la Republica. (2004) Decreto Número 262 de 2004, Enero 28. Por el cual se modifica la estructura del Departamento Administrativo Nacional de Estadística DANE y se dictan otras disposiciones.

Puente, J. (2008) Análisis crítico de los cambios registrados en la legislación ambiental colombiana durante el presente gobierno. En XI Seminario internacional del medio ambiente y desarrollo sostenible. Universidad Industrial de Santander. 15, 16 y 17 de octubre de 2008. Publicaciones UIS.

Rodríguez, M. (1995) "La política ambiental del gobierno Samper". En: Revista Estrategia económica y financiera. №. 205: 25-27

Rodríguez, M. (2007) "La política ambiental en el proyecto del "Plan Nacional de Desarrollo: 2006-2010". Disponible en: http//www.manuelrodriguezbecerra.org/politicaambiental.htm

Rodríguez, M. (2010) "¿Hacer más verde al estado colombiano?". En: Quince años de la política ambiental en Colombia. Universidad Nacional de Colombia (Sede Bogotá) Facultad de Derecho, Ciencias Políticas y Sociales. Instituto 
Unidad de Investigaciones Jurídico-Sociales Gerardo Molina - UNIJUS.

Sandoval, J. (2003) "Lo público, el Estado y la política social". En: Giraldo, C. (Comp.) Rescate de lo Público. Poder financiero y derechos sociales. Ediciones desde abajo.

Talero, S. (2007) "Razón, necesidad y utilidad de la contabilidad ambiental para la sostenibilidad: aproximaciones teóricas". En: Revista Contaduría Universidad de Antioquia, № 50 : 155-176.

Tinbergen, J. \& Hueting, R. (1994) El PNB y los precios del mercado. Señales erróneas de un éxito económico sostenible que encubre la destrucción ambiental. En: Desarrollo Económico Sostenible. Avances sobre el Informe Brundtland. Bogotá: Uniandes: 93-106.

Tobasura, I. (2006) "La política ambiental en los planes de desarrollo en Colombia 1990-2006. Una visión crítica". En: Revista Luna Azul, Universidad de Caldas, № 22: 8-19.

Torres, J., Santiago, M., Matus, J. \& Romo, J. (2001) "Las cuenta nacionales y el medio ambiente". En: Revista Chapingo. Serie ciencias forestales y del ambiente, Universidad Autónoma Chapingo, 7 (001): 67-76.

Tréllez, E. (2002) "La educación ambiental comunitaria y la prospectiva: una alianza de futuro". En: Tópicos en educación ambiental, 4 (10): 7-21.

Turco, J. (2012) Informe de Coyuntura No 5: ¿Desarrollo Sustentable? Según el cristal. En: Informe de Coyuntura: cambio climático. Secretaria de Relaciones Internacionales, Central de Trabajadores de la Argentina. Disponible en: http://www. ctainternacionales.org/wp-content/uploads/2012/03/InformeCoyuntura-Desarrollo-Sustentable.pdf

Uricoechea, F. (2001) "Lo público: historia y estructura". En: Revista TRANS: Lo público y lo privado, Universidad Nacional de Colombia, $N^{\circ}$ 1: 44-54.

Weber, M. (1969) La ética protestante y el espíritu del capitalismo. Barcelona: Editorial Península. 